\title{
DEMAND SIDE MANAGEMENT FOR RESIDENTIAL CONSUMERS CONSIDERING DISTRIBUTION SYSTEM REQUIREMENTS
}

\author{
A Thesis by \\ Thanappuhettige Nipuna Mihiranga Gomes \\ Bachelor of Science, Southeast Missouri State University, 2013
}

Submitted to the Department of Electrical Engineering and Computer Science and the faculty of the Graduate School of

Wichita State University

in partial fulfillment of

the requirements for the degree of

Master of Science

December 2017 
(C) Copyright 2017 by Thanappuhettige Nipuna Mihiranga Gomes

\author{
All Rights Reserved
}




\section{DEMAND SIDE MANAGEMENT FOR RESIDENTIAL CONSUMERS CONSIDERING DISTRIBUTION SYSTEM REQUIREMENTS}

The following faculty members have examined the final copy of this thesis for form and content and recommend that it be accepted in partial fulfillment of the requirement for the degree of Master of Science with a major in Electrical Engineering.

Visvakumar Aravinthan, Committee Chair

Thomas K. DeLillo, Committee Member

Edwin Sawan, Committee Member 


\section{DEDICATION}

To my parents, my wife, and my brother 


\section{ACKNOWLEDGEMENTS}

I would like to sincerely thank my advisor, Dr. Visvakumar Aravinthan for his support, time, kindness and guidance he has shown me since the first day of my graduate studies at Wichita State University. His assistance over the years has helped me immensely to succeed in my academic career. I would also like to thank Dr. Edwin Sawan for being a great teacher and also being a great friend. The friendship we have grown beyond the academic field has meant a lot to me. The experience and ideas I got from the optimization \& theory class with Dr. Thomas DeLillo helped me to understand my research well. Thank you, Dr. DeLillo, for your time and help besides your busy schedule to attain my research problems to success in my thesis.

In addition, I would like to thank Department of Electrical Engineering and Computer Science at Wichita State University for the support the faculty and friends shown me during my time here.

Last but not least, I would like to thank Anton for helping me with this thesis and my dear wife, Nimanthi for her support and patience throughout this journey. 


\begin{abstract}
One of the focus areas of the smart-grid initiative is residential level demand response. Literature presents numerous demand response and load control programs. Some of the recent surveys analyze price-responsive demand response optimization, mathematical modeling of demand response, responsive demand forecasting, and communication requirements. Minimal work is done to evaluate and incorporate the impact of such programs on the grid. The real-time demand response program should benefit both utility and the consumers in an optimized manner. Most demand response schemes in the literature fail to identify the benefit to the distribution system. Only a few of publications in the literature indicate that the proposed demand response programs could benefit the utility. Of that, only a handful of work shows and verifies the actual benefits. One of the works, which evaluated the grid impact, focuses on individual appliances and their contribution to voltage drop mitigation. Regardless of the benefit to the consumers, the utility will not be interested in those programs if they do not provide a considerable benefit to them. This has limited the distribution system operators from identifying the worth of demand response and launch programs which are beneficial to both consumers and distribution operators.

This thesis addresses the value of demand response programs to the grid. The first part of this thesis identifies the benefit of the demand response programs available in the literature. Next, the thesis presents an approach to incorporate utility focused demand response benefits into distribution system operation. This is done by maintaining distribution level requirements such as minimal deviations in nodal voltage and power factor. A modified AC distribution power-flow method is proposed along with the demand response as a constraint. The demand response constraint is developed using the first part. The outcome of this work can be used by utilities to evaluate the benefits of demand response programs
\end{abstract}




\section{TABLE OF CONTENTS}

Chapter

Page

1. INTRODUCTION

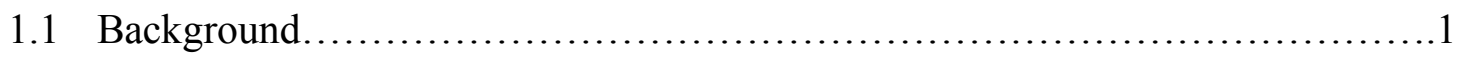

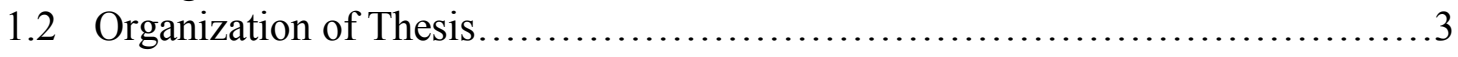

2. LITERATURE REVIEW 4

2.1 Demand Side Management ....................................................................

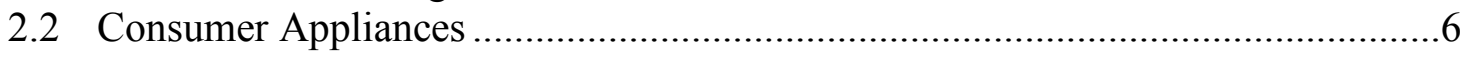

3. PROPOSED MODELING $\quad 8$

3.1 Consumer Appliances Data......................................................................... 8

3.1.1 Basic Household Load Modeling................................10

3.1.2 Heating, ventilation and air-condition........................... 10

3.1.3 Solar Panel......................................................... 11

3.2 Schedulable Load Modeling ............................................. 11

3.2.1 Electric Iron................................................. 12

3.2.2 Programmable Dishwasher.......................................................... 12

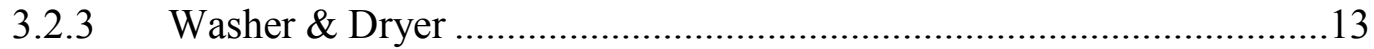

3.2.4 Random Appliance ........................................................................ 13

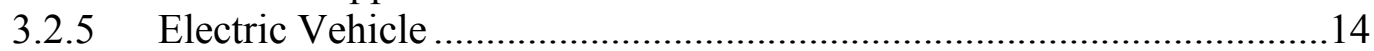

3.3 Modified AC Power Flow Model .................................................................... 14

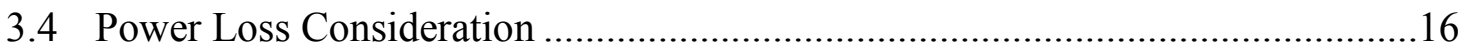

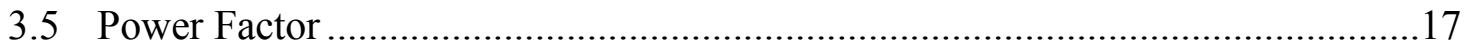

3.6 Appliances Rescheduling .......................................................................... 17

4. AGGREGATOR LEVEL MODELING 20

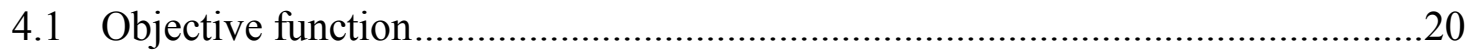

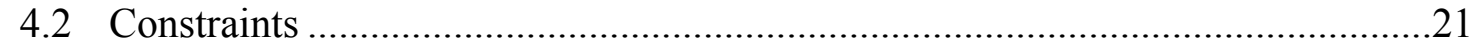

5. NUMERICAL ANALYSIS $\quad 25$

6. CONCLUSION AND FUTURE WORKS 42

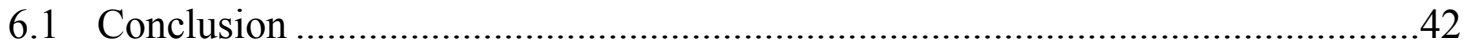

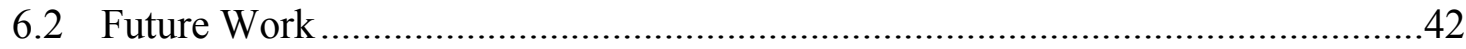


TABLE OF CONTENTS (continued)

Chapter

Page

7. REFERENCES 


\section{LIST OF FIGURES}

Figure

Page

2.1: Classification of demand response programs ........................................................... 5

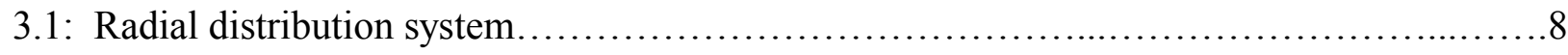

3.2: Power flow between two adjacent nodes ............................................................. 14

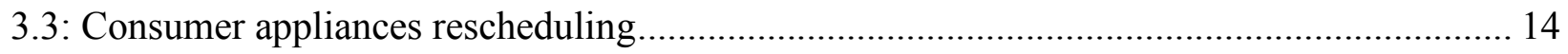

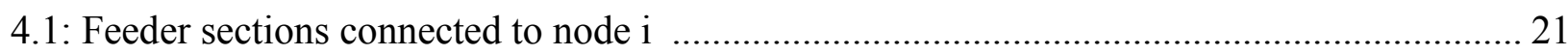

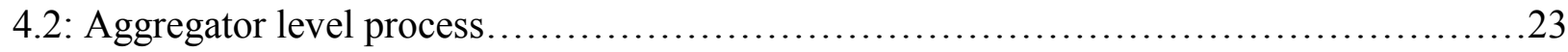

5.1: IEEE four node distribution test feeder ............................................................. 25

5.2: Optimization using built-in fmincon function ..................................................... 25

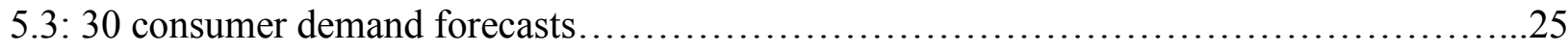

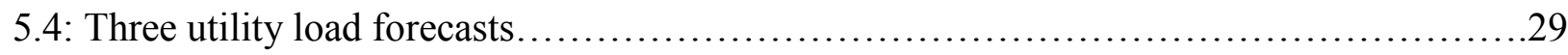

5.5: Node voltages for utility forecast 01 without reschedule $\ldots \ldots \ldots \ldots \ldots \ldots \ldots \ldots \ldots \ldots \ldots . \ldots \ldots$

5.6: Node voltages for utility forecast 01 with reschedule................................

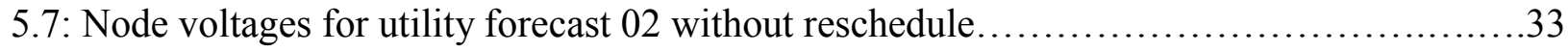

5.8: Node voltages for utility forecast 02 with reschedule............................... 33

5.9: Node voltages for utility forecast 03 without reschedule............................ 34

5.10: Node voltages for utility forecast 03 with reschedule $\ldots \ldots \ldots \ldots \ldots \ldots \ldots \ldots \ldots \ldots \ldots \ldots . \ldots \ldots$

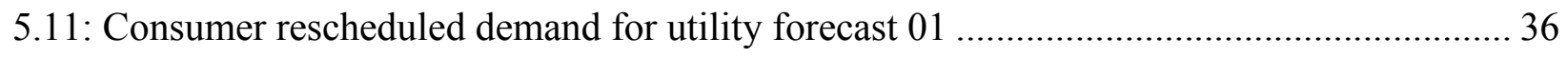

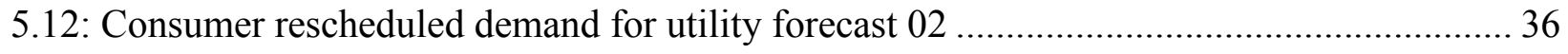

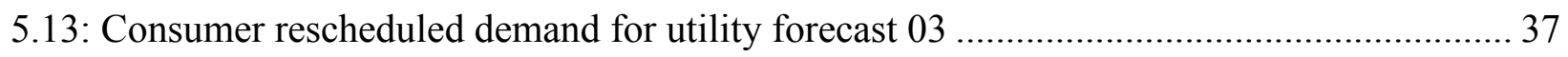

5.14: Average number of times that the rescheduled forecast higher than utility forecast.......... 38

5.15: Average Energy Usage Over forecast.................................................................. 38 


\section{LIST OF FIGURES (continued)}

Figure $\quad$ Page

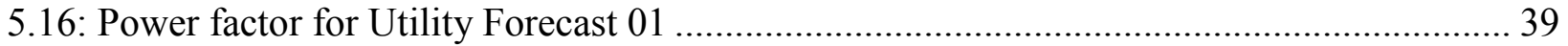

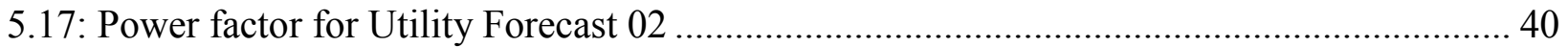

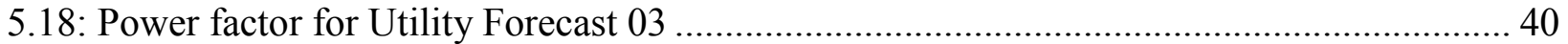




\section{LIST OF TABLES}

Table

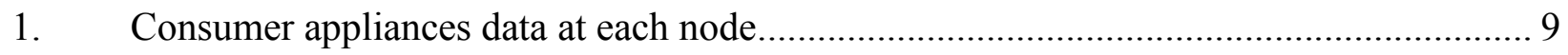

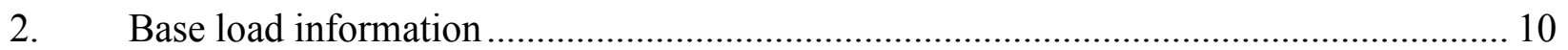

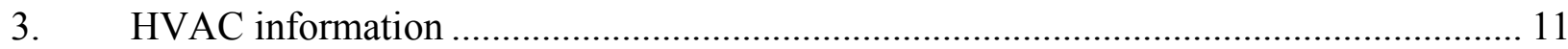

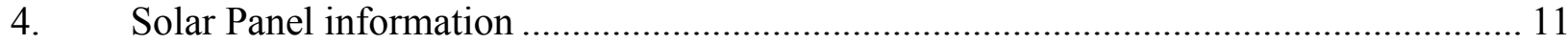

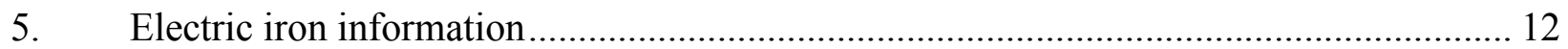

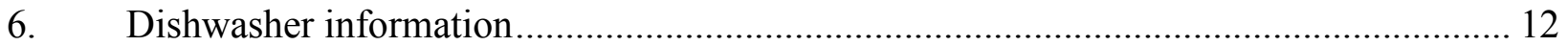

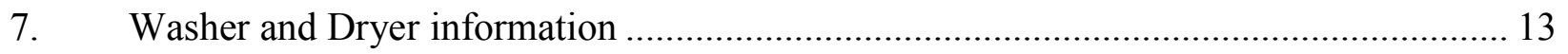

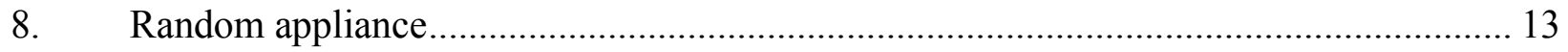

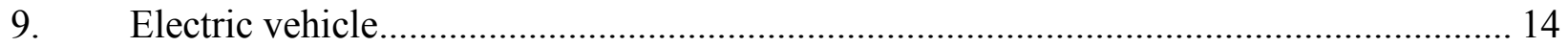

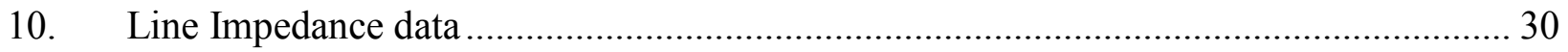

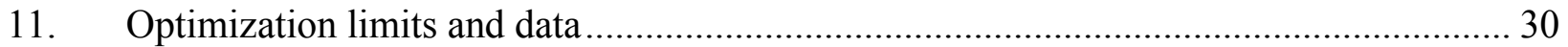

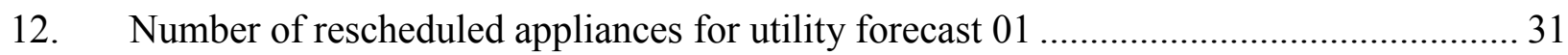

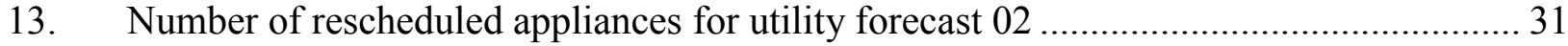

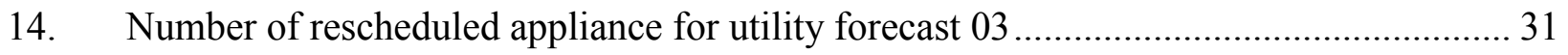




\section{LIST OF ABBREVIATIONS}

$\begin{array}{ll}\text { ANSI } & \text { American National Standards Institute } \\ \text { ASHRAE } & \text { American Society of Heating, Refrigerating and Air Conditioning Engineers } \\ \text { DG } & \text { Distributed Generation } \\ \text { DSM } & \text { Demand Side Management } \\ \text { DR } & \text { Demand Response } \\ \text { HVAC } & \text { Heating, Ventilation and Air conditioning } \\ \text { IEEE } & \text { Institute of Electrical and Electronics Engineers } \\ \text { PV } & \text { Photovoltaics }\end{array}$




\section{CHAPTER 1}

\section{INTRODUCTION}

\subsection{Background}

According to a report by the World Bank Group report, 85 percent of the world population has access to electricity [1]. Therefore, this is the optimum time for power system engineers to see a fast growth in the current grid system out of its long-established methods. The flat rate pricing system used by the utilities has been rooted far too long and has been ingrained into the minds of both the utility and the consumer. For them, the only way they could reduce the usage of energy is to reduce the utilization of electricity. While most countries still use a flat rate unit price to bill their electricity consumers, the USA is breaking free from this traditional flat fee pricing scheme.

New developments in many power system modules have steered utility companies to serve more reliable and stable power to their end users. Because of this added observability in the system the utility has gained the control over their distribution system and uses its real-time data management system to identify system overloads, the demand profile's shape depending on the time and many more [2]. To serve their customers better, the utility has incorporated a tool called Demand Side Management (DSM) to evolve in its conventional methods of generation, transmission, and distribution [2]. The simplest idea of a DSM program is the understanding of customer behaviors, the unpredictability of their electricity consumption and giving a choice to customers to adjust their use of electric appliances according to the utility requirements. There is currently a small number of utility companies in the US that use some demand response programs. These programs persuade their customers to curtail their peak demands by giving back an incentive payment for changing the accustomed behavior. 
Traditionally, consumers can either demand or decline the power from a utility at any given time of the day to operate their appliances. This dynamic consumer behavior is disadvantageous to a utility compared to controlling consumer appliances. The amount of extra power a utility must produce is much higher as they need to be prepared for such events. Having to keep running standby generation units, or needing to buy extra generation from nearby wholesale electricity sellers to meet the demand results in higher energy prices for the consumers. Generating more power is certainly an option but it is a costly one when considering the environmental impact and the limited access to fossil fuels. Thus, this solution is no longer an option for the current and future grid operations. The growth of Distributed Generations (DGs) may be the solution but it is far from perfect to work standalone in the electricity grid due to its irregular behavior and therefore must be used as a secondary generation alongside more reliable power sources.

Over the years, electricity companies, especially in the United States, have been working on addressing these issues and have implemented successful Demand Side Management (DSM) programs in a number of states. So far, the utilities have implemented various Demand Response Programs (DR) to manage consumer loads under their DSM, to meet the electricity demand effectively as an alternative to increasing their generation.

While a Demand Response Program executed at the consumer level promises to give many advantages to the utility, it is hard to perform without a good amount of customer participation. Also, it is worth noting that how much of load each participating customer is willing to allocate for the utility's decision making is actually the key to a good DR program.

Optimal power flow is used in this thesis for a modified IEEE 4 Bus System, a radial distribution network, to find the optimal power flowing into the nodes according to the given system constraints in parallel with an aggregated load rescheduling model. The proposed 
rescheduling model runs at certain times when consumer forecasted 24-hour load profile is much higher than the utility's historical (Excepted) forecasted load profile. The load rescheduling program will follow the optimal system evaluations to rearrange the consumer appliances accordance to the consumer preferable times to reduce peaks at higher demand times.

\subsection{Organization of Thesis}

This thesis consists of six chapters. Chapter 1 introduces the motivation of the thesis. Literature review on Demand Side Management and Consumer Appliances are discussed in Chapter 2. Proposed modeling is presented in Chapter 3 and Chapter 4 discuss the optimization used. Numerical Analysis is done in Chapter 5 and Chapter 6 concludes this thesis with the conclusion and future work. 


\section{CHAPTER 2}

\section{LITERATURE REVIEW}

\subsection{Demand Side Management}

Recent technological advancements in autonomous controllers, communications, software, data management systems and other fields have given an opportunity to power systems engineers to rethink and improve the current gird from its conventional methods. The introduction of the smart metering system in power systems has given much broader visibility between the consumers and the utility. Utilities can now monitor the consumption of its customers remotely. Moving forward from this initiative, the above said technological advancements have also given benefits to the consumers as well. Utility companies such as Chicago ComEd Marketplace has already started giving instant rebates to the residential customers who are using Energy Star certified appliances, this one of their many benefits they provide to customers who take energy conserving initiatives [3]. ComEd allows its customers to view its current electricity unit price so that they can participate ComEd's DSM program by turning on appliances when the ComEd reduce their electricity price.

A survey on Demand Response Programs in Smart Grids by Vardakas et al. shows the categorization of the various elements of Demand Response Programs in Figure 2.1. 


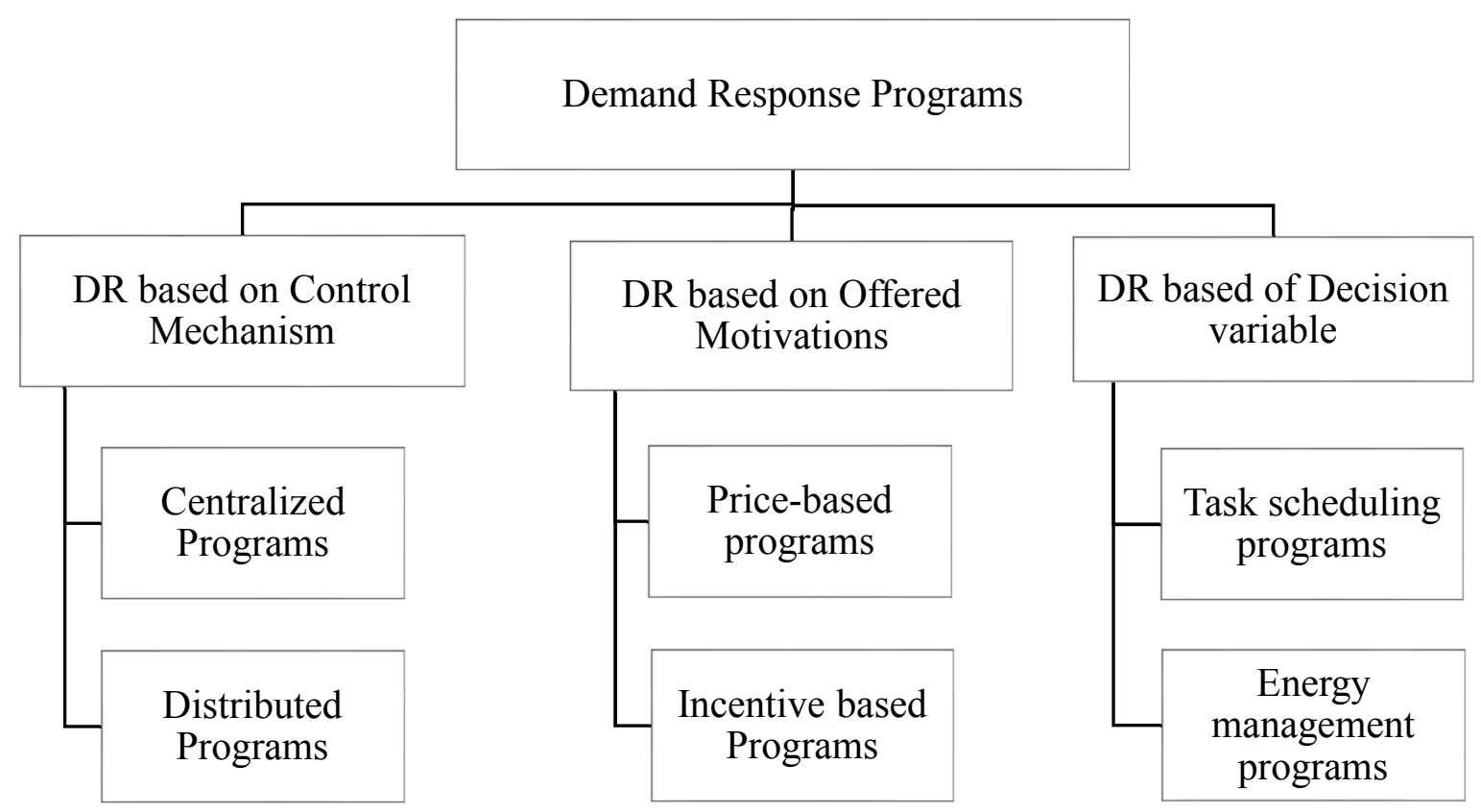

Figure 2.1: Classification of Demand Response programs [1]

DR methods address the controllability of consumer loads by, either gathering consumer data with a centralized scheme or by giving total consumer consumption information to the Utility [2]. Under the "Offered Motivations" category, the authors summarize that utilities allow the consumers to shift their use of appliances according to the price information available from the utility. This is incentivized to encourage consumers to make use of this method and reduce power usage. In the last category, consumers are not incentivized and yet take the responsibility in reducing their power usage by shifting their loads [2].

Varadaks et al. classifies the types of DR optimization techniques and presents a paper by Yang et al. that uses convex optimization to minimize consumption based on system pricing schemes. However, this model does not consider the impact of system requirements in terms of voltage and power factor and is modeled to include only 100 consumers. This has given the motivation for this thesis. 


\subsection{Consumer Appliances}

Yang et al. introduced three main types of loads, base loads, schedulable Load and flexible load. The base load is non-adjustable, and they satisfy the basic consumer needs such as lighting, small electronic appliances, stoves, and refrigerators etc. Schedulable loads meanwhile can be adjusted at the time of the day and do not depend on the total customer satisfaction. For example, a consumer can change their electric vehicle charging time by an hour or to another preferable time and still be able to charge the car fully. Flexible loads are types of appliances that can be used to manage energy consumption in a house. Depending on the electricity price at the time of the day, a user can adjust their temperature setting and still be able to live comfortably. For an example; during a summer day a consumer could adjust their temperature from $72^{\circ} \mathrm{F}$ to a higher setting like $75^{\circ} \mathrm{F}$.

Stamminger et al. [4] have shown detailed information on major domestic consumer appliances in term of their energy consumption as well as other information. [5] has drawn the load profiles for some of these appliances based on their historical data and active customer participation to analyze its impact on the demand. The active customer participation (consumer change their loads when the electricity price is low) for their model has shown how much of load flexibility has impacted the system voltage.

Scheduling consumer appliances on their preference times based on system requirements is evaluated in this thesis. This thesis will model the profiles for appliances that correspond to the following two types.

1) Base Load

2) Schedulable Load 
The base load mentioned in this thesis will contain all other appliance which is not described in the Schedulable loads, including HVAC. 


\section{CHAPTER 3}

\section{PROPOSED MODELING}

Aggregator level load modeling is considered for this thesis. The consumer appliance data is sent to the local aggregator and aggregator is responsible for collecting and rescheduling their consumer appliances according to the utility's response. There are two types houses considered for this model. These are, houses without DGs (n) and houses with DGs (m).

$$
\text { Total Load at Node }(\mathrm{i})=\sum_{\mathrm{n}=1}^{\mathrm{n}}\left(\mathrm{P}_{\mathrm{n}, \mathrm{B}}+\mathrm{P}_{\mathrm{n}, \mathrm{S}}\right)+\sum_{\mathrm{m}=1}^{\mathrm{m}}\left(\mathrm{P}_{\mathrm{m}, \mathrm{B}}+\mathrm{P}_{\mathrm{m}, \mathrm{S}}-\mathrm{P}_{\mathrm{m}, \mathrm{DG}}\right)
$$

Where, $\mathrm{P}_{\mathrm{B}}$, Base Load, $\mathrm{P}_{\mathrm{S}}$, Schedulable Load, $\mathrm{P}_{\mathrm{DG}}$, Distributed Generation

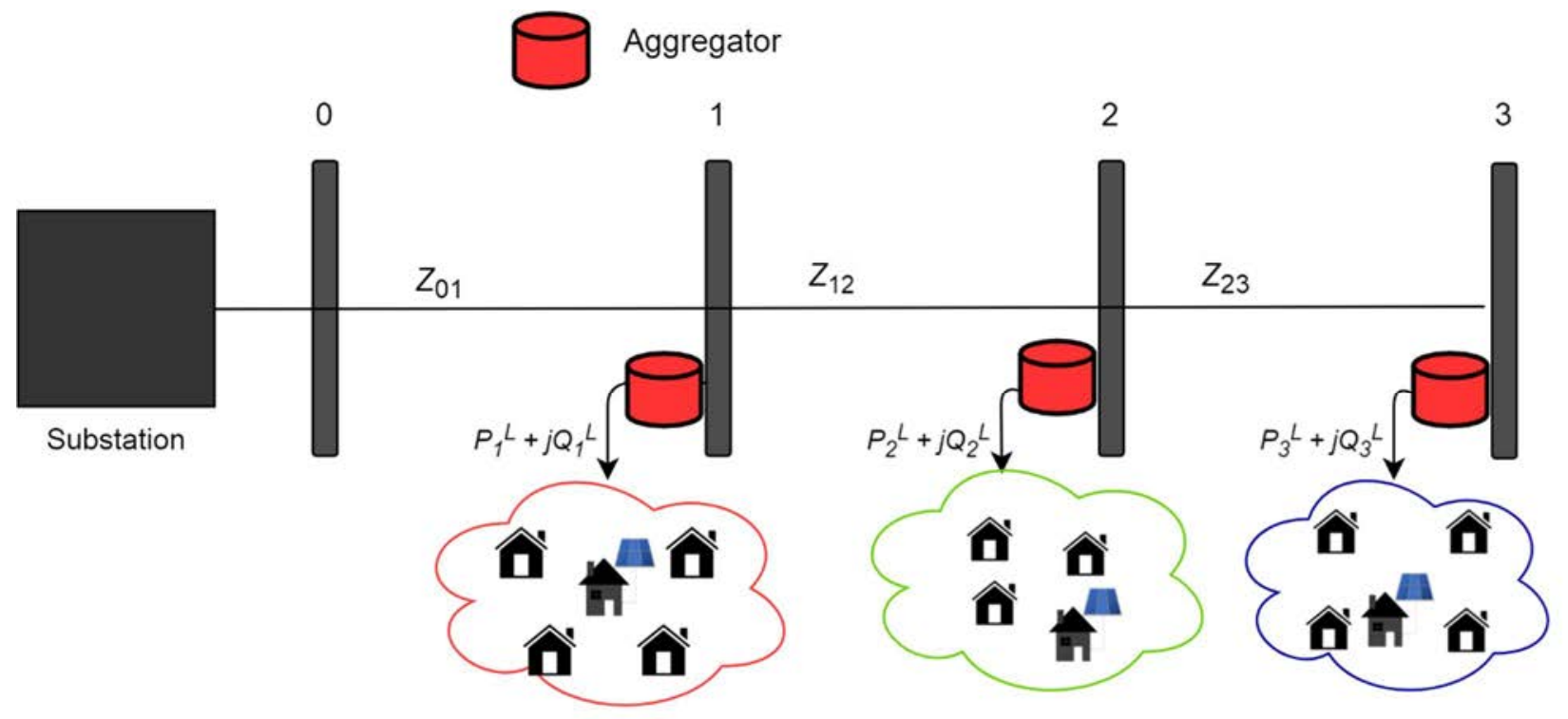

Figure 3.1: Radial Distribution System

\subsection{Consumer Appliances Data}

In this proposed model, 6,000 residential customers were disaggregated to consumer appliance level load profiles to gather data and to find flexible times the consumers tend to use the below individual appliances numbered 1-5 in TABLE 1 . The intent of this disaggregated load 
profiles modeling is to identify the locations or the times of each appliance work. For the feeder level modeling, the aggregated load of these appliances at each node is considered for optimization.

TABLE 1

CONSUMER APPLIANCES DATA AT EACH NODE

\begin{tabular}{|l|c|c|c|}
\hline \multirow{2}{*}{ Load Type } & Node 02 & Node 03 & Node 04 \\
\cline { 2 - 4 } & \multicolumn{3}{|c|}{ Total Participants } \\
\cline { 2 - 4 } & 2000 of Consumers & 1700 of Consumers & 2300 of Consumers \\
\hline Base Load & 2000 & 1700 & 2300 \\
\hline HVAC & 1900 & 1700 & 2100 \\
\hline Electric Iron & 1500 & 1500 & 1300 \\
\hline $\begin{array}{l}\text { Programmable } \\
\text { Dishwasher }\end{array}$ & 1000 & 600 & 800 \\
\hline Washer \& Dyer & 1200 & 900 & 1200 \\
\hline Random appliance & 2000 & 1700 & 2300 \\
\hline Electric Vehicle & 35 & 35 & 20 \\
\hline Distributed Generation & 25 & 20 & 20 \\
\hline
\end{tabular}

Total of 6000 customers is divided among the node 2, node 3 and node 4 by 2000, 1700 and 2300 customers respectively. It is also considered that not every household has or use every single appliance listed above on any given day. Therefore, when modeling, the total number of load types have been changed to be less than the total number of consumers from node to node. However, a random appliance is introduced to this model, where, consumers are indeed able to use their choice of equipment according to the utility rescheduled times. 


\subsubsection{Basic Household Load Modeling}

For base household load modeling, it assumed that every single house at each node demands some power from the utility to operate their basic human needs without being having to sacrifice their comfort or the behavior.

TABLE 2

BASE LOAD INFORMATION

\begin{tabular}{|l|l|c|}
\hline & $\begin{array}{l}\text { Real Power } \\
(15 \mathrm{~min})\end{array}$ & Requested time \\
\hline Node 02 & $0.25 \sim 0.05 \mathrm{~kW}$ & 24 hours \\
\hline Node 03 & $0.25 \sim 0.05 \mathrm{~kW}$ & 24 hours \\
\hline Node 04 & $0.25 \sim 0.05 \mathrm{~kW}$ & 24 hours \\
\hline
\end{tabular}

From small lighting appliances, stove to the refrigerator, the non-schedulable load is separated from schedulable loads to ensure the customers are providing with enough demand for day to day basic activities. Since these loads are non-schedulable, they are listed to be operated for 24 hours in the consumer forecast demand report.

\subsubsection{Heating, ventilation and air-condition}

The HVAC is selected as a baseload because of its complexity of modeling and the consumer comfort. The ASHRAE standard 55, that comes along with it made the modeling dynamic behavior for HVAC is more complex [6]. Depending on the consumer living space measurements, the duration of its operating cycles, number of people living in a house and other factor, the HVAC is decided to be considered as a base load in this thesis. 
TABLE 3

HVAC INFORMATION

\begin{tabular}{|c|c|c|}
\hline & $\begin{array}{l}\text { Real Power } \\
(15 \mathrm{~min})\end{array}$ & Requested time \\
\hline Node 02 & $\sim 0.050 \mathrm{~kW}$ & 24 hours \\
\hline Node 03 & $\sim 0.050 \mathrm{~kW}$ & 24 hours \\
\hline Node 04 & $\sim 0.050 \mathrm{~kW}$ & 24 ours \\
\hline
\end{tabular}

\subsubsection{Solar Panel}

Rooftop solar panels are considered for modeling purposes. The idea of having some DGs at each node to separate regular houses with houses with DGs. For a larger number of consumers, the impact of DGs are rather small and assumed that extra power generated from the DGs are consumed within the node; hence there is no reverse power flow. Hence it reduces the complexity of modeling the DGs at radial distribution feeder.

TABLE 4

SOLAR PANEL INFORMATION [7]

\begin{tabular}{|c|c|c|}
\hline & $\begin{array}{l}\text { Real Power } \\
(15 \mathrm{~min})\end{array}$ & Operational time \\
\hline Node 02 & $0 \sim 0.88 \mathrm{~kW}$ & $\sim 9$ hours \\
\hline Node 03 & $0 \sim 0.88 \mathrm{~kW}$ & $\sim 9$ hours \\
\hline Node 04 & $0 \sim 0.88 \mathrm{~kW}$ & $\sim 9$ hours \\
\hline
\end{tabular}

\subsection{Schedulable Load Modeling}

The Schedulable loads are modeled for every single house, based on their requested time of operation. Once the simulation is started, these appliances will be rescheduled to the following schedulable time periods as preferred by the corresponding consumers. In this thesis, we assumed that the requested time period and schedulable time period are the same for Electric Iron, Random 
Appliance, and Electric Vehicle while Programmable Dishwasher and the Washer and Dryer have given proffered time period because of their autonomous nature once programmed.

\subsubsection{Electric Iron}

Electric Iron is considered as a reschedulable load for modeling purposes in this thesis. The frequency of use per day is assumed to be once and it is also assumed that it would be used for 30 minutes for a single household. The power and the time schedules are listed in the table 5 .

TABLE 5

ELECTRIC IRON INFORMATION

\begin{tabular}{|c|c|c|c|}
\hline & $\begin{array}{c}\text { Real Power } \\
(15 \mathrm{~min})\end{array}$ & Requested period & Schedulable period \\
\hline Node 02 & $0.35 \sim 0.23 \mathrm{~kW}$ & $6 \mathrm{AM}-10 \mathrm{PM}$ & $6 \mathrm{AM}-10 \mathrm{PM}$ \\
\hline Node 03 & $0.35 \sim 0.23 \mathrm{~kW}$ & $6 \mathrm{AM}-8 \mathrm{PM}$ & $6 \mathrm{AM}-10 \mathrm{PM}$ \\
\hline Node 04 & $0.35 \sim 0.23 \mathrm{~kW}$ & $6 \mathrm{AM}-10 \mathrm{PM}$ & $6 \mathrm{AM}-10 \mathrm{PM}$ \\
\hline
\end{tabular}

\subsubsection{Programmable Dishwasher}

The frequency of use of programmable dishwasher per day is assumed to be once and it is assumed that it would be used for 150 minutes as shown in table 6, for a single household [8].

TABLE 6

DISHWASHER INFORMATION

\begin{tabular}{|c|c|c|c|}
\hline & $\begin{array}{c}\text { Real Power } \\
(15 \mathrm{~min})\end{array}$ & Requested period & Schedulable period \\
\hline Node 02 & $0.75 \sim 0.35 \mathrm{~kW}$ & 2 PM - 5 AM & 2 PM - 6 AM \\
\hline Node 03 & $0.75 \sim 0.35 \mathrm{~kW}$ & $8 \mathrm{AM}-6$ PM & 6 AM - 10 PM \\
\hline Node 04 & $0.75 \sim 0.35 \mathrm{~kW}$ & $2 \mathrm{PM}-5 \mathrm{PM}$ & $12 \mathrm{PM}-6 \mathrm{AM}$ \\
\hline
\end{tabular}




\subsubsection{Washer \& Dryer}

The frequency of use per day is assumed to be once for washer and dryer and it is assumed that it would be used for 90 minutes as shown in table 7 for a single household [9] [10].

TABLE 7

WASHER AND DRYER

\begin{tabular}{|c|c|c|c|}
\hline & $\begin{array}{c}\text { Real Power } \\
(15 \mathrm{~min})\end{array}$ & Requested time & Schedulable time \\
\hline Node 02 & $0.90 \sim 0.75 \mathrm{~kW}$ & $9 \mathrm{AM}-10 \mathrm{PM}$ & $6 \mathrm{AM}-11 \mathrm{PM}$ \\
\hline Node 03 & $0.90 \sim 0.75 \mathrm{~kW}$ & $10 \mathrm{AM}-3 \mathrm{AM}$ & $10 \mathrm{AM}-6 \mathrm{AM}$ \\
\hline Node 04 & $0.900 .75 \mathrm{~kW}$ & $9 \mathrm{AM}-10 \mathrm{PM}$ & $6 \mathrm{AM}-11 \mathrm{PM}$ \\
\hline
\end{tabular}

\subsubsection{Random Appliance}

A choice of applaince is given to the consumers considering their satisfaction and must be used within the rescheduable times given by the utility. The frequency of use per day is assumed to be once a day and it is assumed that it would be used for 60 minutes for a single household as shown in table 8 .

TABLE 8

RANDOM APPLIANCE

\begin{tabular}{|c|c|c|c|}
\hline & $\begin{array}{c}\text { Real Power } \\
(15 \mathrm{~min})\end{array}$ & Requested time & Schedulable time \\
\hline Node 02 & $0.4 \sim 0.2 \mathrm{~kW}$ & $6 \mathrm{AM}-11 \mathrm{PM}$ & $6 \mathrm{AM}-11 \mathrm{PM}$ \\
\hline Node 03 & $0.4 \sim 0.2 \mathrm{~kW}$ & $6 \mathrm{AM}-10 \mathrm{PM}$ & $6 \mathrm{AM}-10 \mathrm{PM}$ \\
\hline Node 04 & $0.4 \sim 0.2 \mathrm{~kW}$ & $6 \mathrm{AM}-11 \mathrm{PM}$ & $6 \mathrm{AM}-11 \mathrm{PM}$ \\
\hline
\end{tabular}




\subsubsection{Electric Vehicle}

The frequency of use per day is assumed to be once a day and it is assumed that it would be used for 4 hours to charge for a single household. The average real power required to charge the vehicle and duration of the requested time periods are shown in table 9.

TABLE 9

ELECTRIC VEHICLE

\begin{tabular}{|c|c|c|c|}
\hline & $\begin{array}{c}\text { Real Power } \\
(15 \mathrm{~min})\end{array}$ & Requested time & Schedulable time \\
\hline Node 02 & $1.65 \sim 1.13 \mathrm{~kW}$ & $6 \mathrm{PM}-6 \mathrm{AM}$ & $6 \mathrm{PM}-6 \mathrm{AM}$ \\
\hline Node 03 & $1.65 \sim 1.13 \mathrm{~kW}$ & $5 \mathrm{PM}-6 \mathrm{AM}$ & $5 \mathrm{PM}-6 \mathrm{AM}$ \\
\hline Node 04 & $1.65 \sim 1.13 \mathrm{~kW}$ & $6 \mathrm{PM}-6 \mathrm{AM}$ & $6 \mathrm{PM}-6 \mathrm{AM}$ \\
\hline
\end{tabular}

\subsection{Modified AC Power Flow Model}

A simplified version of power flow model is derived from the original optimal power flow equations presented in [11] and since this thesis does not consider the cost of utility power generation, the optimality for utility is not discussed. However, the distribution system constraints such as standard Nodal Voltages and Power Factors are considered as hard constraints for the system-wide optimality.

A one-way power flow is considered in this thesis. The power coming out of the substation will go to all the nodes to supply the demand.

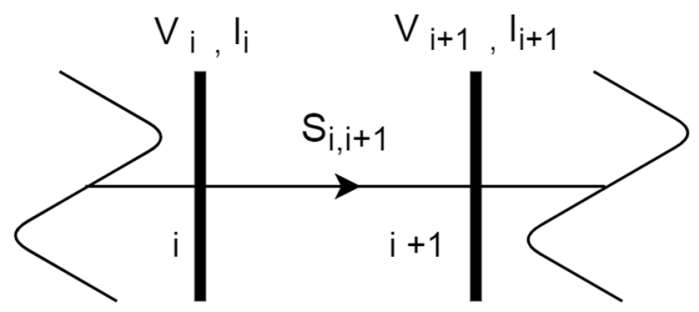

Figure 2.2: Power flow between two adjacent nodes 
The complex power flow through the lines is modeled. For generalization, the equation for the power flow between two adjacent bus or the nodes $i$ and $(i+1)$ can be written as follows.

$$
S_{i, i+1}=V_{i, i+1} I_{i, i+1}^{*}
$$

where,

$V_{i, i+1}$ is the voltage drop between node $i$ and $(i+1)$; and $I_{i, i+1}^{*}$ is the current flow from node $i$ and $(i+1)$. Using, Ohm's law $V=I Z$, bus voltage magnitude $\left(V_{i}\right)$ and voltage angle $\left(\theta_{i}\right)$, the above equation can be rewritten as follows,

$$
S=\frac{V_{i}^{2}-V_{i} V_{i+1}\left(\cos \left(\theta_{i+\Gamma} \theta_{i}\right)+j \sin \left(\theta_{i+\Gamma} \theta_{i}\right)\right)}{Z_{i, i+1}^{*}}
$$

where,

$$
Z=r+j x
$$

Resistance is denoted by " $r$ " and reactance by " $x$ ",

$$
Z^{*}=r-j x
$$

And can be rewritten as,

$$
S=\frac{\left[V_{i}^{2}-V_{i} V_{i+1}\left(\cos \left(\theta_{i+1}-\theta_{i}\right)+j \sin \left(\theta_{i+1}-\theta_{i}\right)\right)\right]\left(r_{i, i+1}+j x_{i, i+1}\right)}{r_{i, i+1}^{2}+x_{i, i+1}^{2}}
$$

By separating real and imaginary parts, we can obtain the real power flow equation 3.7 and reactive power flow equation 3.8 below.

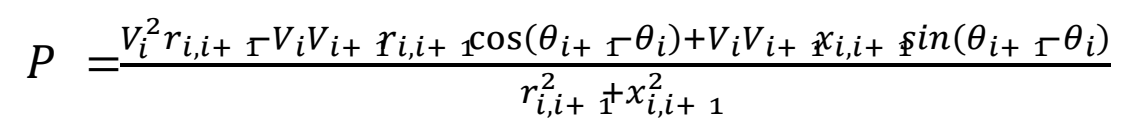

and

$$
Q=\frac{j V_{i}^{2} x_{i, i+\Gamma j} V_{i} V_{i+1} x_{i, i+} \operatorname{fos}\left(\theta_{i+\Gamma} \theta_{i}\right)-j V_{i} V_{i+\Upsilon} \Upsilon_{i, i+} \sin \left(\theta_{i+\Gamma} \theta_{i}\right)}{r_{i, i+1}^{2} x_{i, i+1}^{2}}
$$


It is considered that the voltage angle is small between two nodes along the distribution feeder during steady state operation [11]. Therefore, the following assumption is made.

$$
\cos \left(\theta_{\mathrm{i}+1}-\theta_{\mathrm{i}}\right)=1
$$

Because the difference is so small and when it is close to zero, the Cos $(\sim 0) \rightarrow 1$.

Also, for $\operatorname{Sin}$ terms, we assume that $\operatorname{Sin}\left(\theta_{\mathrm{i}+1}-\theta_{\mathrm{i}}\right)=\delta$ because the angle difference between two buses is so small and measured in radians, and when it is close to zero, but not zero,

$$
\operatorname{Sin}\left(\theta_{i+1}-\theta_{i}\right) \rightarrow \text { just the } \theta_{+1}-\theta_{i}=\delta
$$

Based on the above assumptions, and then substituting each relevant notation, the following final equations can be derived from real (equation 3.11) and reactive power (equation 3.12) flows.

$$
P_{i, i+1}=\frac{V_{i}\left(\left(V_{i+1}-V_{i}\right) r_{i, i+1}+\delta_{i, i+1} V_{i+1} x_{i, i+1}\right)}{r_{i, i+1}^{2}+x_{i, i+1}^{2}}
$$

and

$$
Q_{i, \mathrm{i}+1}=\frac{j V_{i}\left(\left(V_{i+\Gamma} V_{\mathrm{i}}\right) \boldsymbol{x}_{i, \mathrm{i}+1}+\delta_{\left.i, \mathrm{i}+Y_{\mathrm{i}}+r_{i, \mathrm{i}+1}\right)}\right.}{r_{i, \mathrm{i}+\mathrm{1}}^{2}+x_{i, \mathrm{i}+1}^{2}}
$$

The above two equations are used as real power and reactive power flow constraints in the optimization section.

\subsection{Power Loss Consideration}

It is assumed that other equipment along the transmission lines have negligible impedance and do not add substantial losses to overall system impedance. Therefore, line loss between two nodes along the copper conductor can be calculated as follows,

$$
\mathrm{P}_{\mathrm{i}, \mathrm{i}+1}^{\mathrm{Loss}}=\mathrm{r}_{\mathrm{i}, \mathrm{i}+1}\left|\mathbf{I}_{\mathrm{i}, \mathrm{i}+1}\right|^{2}
$$


by substituting Ohm's law

$$
P_{\text {loss }}=\frac{r_{i, i+1}\left(V_{i}^{2}+V_{i+1}^{2}-2 V_{i} V_{i+1} \cos \left(\theta_{i+1} \theta_{i}\right)\right)}{\left(r_{i, \mathrm{i}+1}^{2}+x_{i, \mathrm{i}+1}^{2}\right)}
$$

And by using the assumptions of the voltage angle is small between two nodes along the distribution feeder as above, equation 3.14 is obtained

$$
P_{l o s}=\frac{r_{i, i+}\left(V_{i}^{2}+V_{i+1}^{2}-2 V_{i} V_{i+1}\right)}{\left(r_{i, \mathrm{i}+1}^{2}+x_{i, \mathrm{i}+1}^{2}\right)}
$$

The power loss at distribution level is considered in the power flow model to improve the accuracy of the proposed model only.

\subsection{Power Factor}

The power factors, Cos $\alpha$ at the nodes are calculated by the following equation.

$$
\operatorname{Cos} \alpha=\frac{P_{i}}{S_{i}}
$$

Where $\mathrm{P}$ is real power flowing into the node and $\mathrm{S}$ is the apparent power.

\subsection{Appliances Rescheduling}

The control of these appliances has increased further by up to 4 times. A single one-hour period has been divided into 4 quadrants of 15-minute time frames to control an appliance more effectively.

By doing so, it helps to reduce the energy loss by not wanting to generate for next $45,30,15$ minutes if an appliance is switched off by hour and quarter. For an example, if an appliance, like washer and dryer both works for around 80 minutes in total. That is, in fact, one hour and 20 minutes. If the scheduling control in done hourly, the utility must supply the demand for next two 
hours. Since the control is now designed for a 15-minute time interval, the utility can easily stop supplying the extra power for the next 30-minute time period.

However, on the downside of this control is that it takes much more computational time to obtain acceptable results. Therefore, it needs to be controlled by limiting the number of runs it takes to scheduling appliances and the number of times it spends on rescheduling the same time interval.

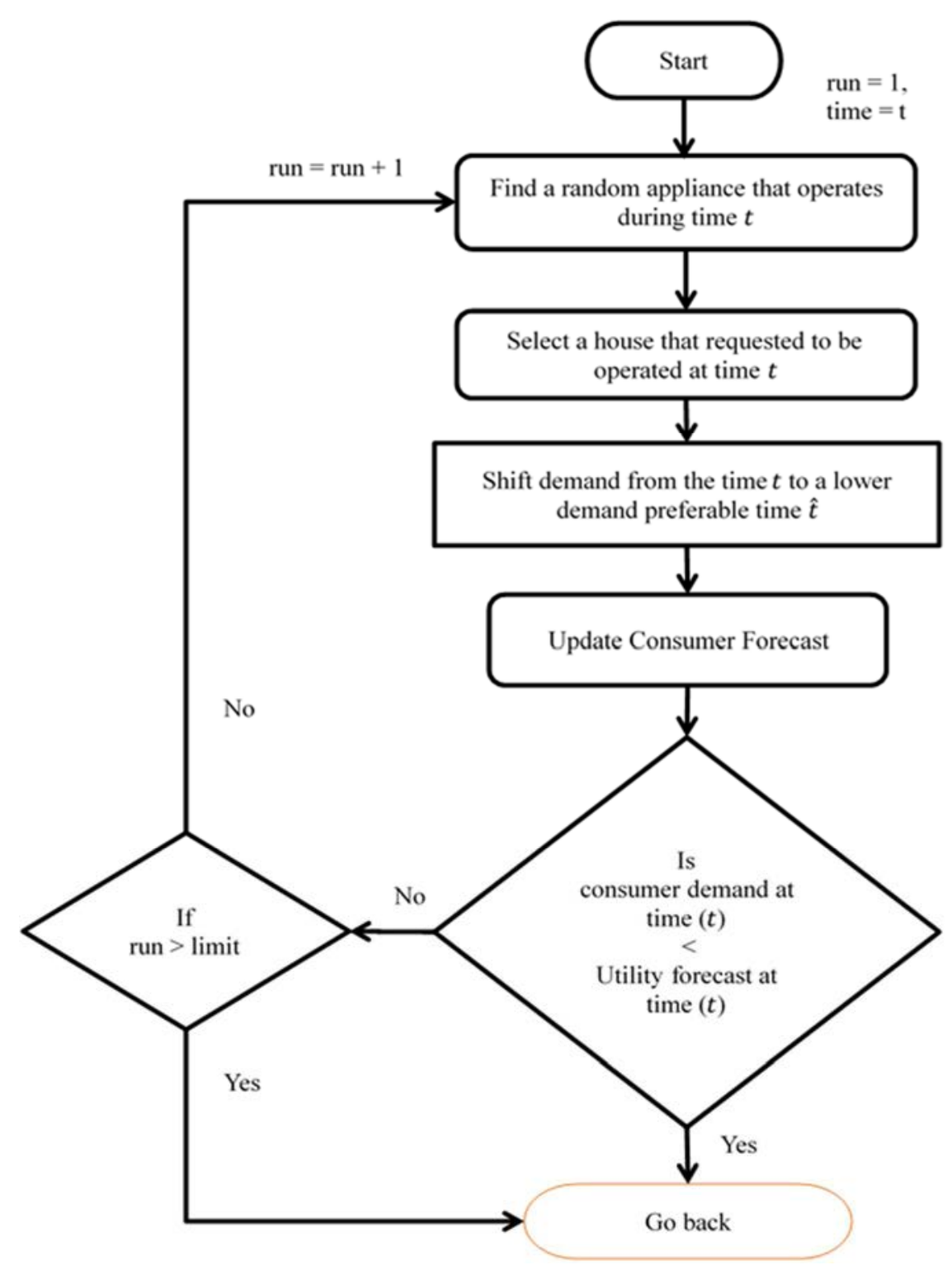

Figure 3.3: Consumer Appliances Rescheduling 
The rescheduling model is designed for consumers with schedulable appliances. Once the location of the individual appliance is known, the process starts for time $t$, a time interval where the utility forecast is lower than consumer requested forecast. The next step is to find random appliance that requested to be working for time $t$. An aggregator then finds a house that would use the selected appliance and rescheduled it to different time $\hat{t}$. Once the rescheduling is completed for an appliance, the information is updated to the system. This is done after rescheduling is occurred to ensure that consumer forecast data are up to date. Once the rescheduling is completed, it would check if the consumer forecast is higher than what utility forecasted, and if it is true, the model will run for maximum of 20 reschedules at each time $t$ to reduce the consumer forecast load from time $t$ to another time locations $\hat{t}$. The limit is there to ensure to complete the rescheduling appliances within a timeframe and considers the consumer satisfaction by limiting the number of appliances to be scheduled. Once the rescheduling is completed, the program goes back to the optimization model and must restarts it to run from the beginning since the appliances now have been rescheduled to different time intervals. 


\section{CHAPTER 4}

\section{AGGREGATOR LEVEL MODELING}

\subsection{Objective function}

The objective of this overall model is to supply the consumer forecasted loads close to the utility forecasted load and keeping the local adjacent nodal voltages close to one per unit. Therefore, a multi-objective function is developed to address all above requirements.

I. The overall forecasted power difference between the aggregated nodal real power and the utility's substation forecasted load is minimized. It is assumed that the utility forecast is based on its historical data and also by the available scheduled generation for tomorrow. The objective of the utility is to operate their generation units as forecasted and if at times the utility is unable to serve because of higher demand from the consumers, the consumer load is rescheduled at a secondary stage.

$$
\min _{\mathrm{P}}(P)=\left(P_{\eta}^{s s}-\sum_{i=1}^{n} P_{i}\right)^{2}
$$

II. To keep the operational voltage magnitude throughout the system close to substation required voltage levels, adjacent nodal voltage deviations are minimized and kept close to 1 per unit. This helps the substation to operate in an established manner as expected and also to provide steady power supply to the consumers without damaging their appliances.

$$
\min _{\mathrm{V}_{\mathrm{i}}}(\Delta \mathrm{V})^{2}=\sum_{i=1}^{n}\left(\mathrm{~V}_{i}-\overline{\mathrm{V}}_{1}\right)^{2}
$$


The multi-objective function follows, after including all the above individual objectives.

$$
\min _{\mathrm{P}, V_{i}}\left(P_{\eta}^{s s}-\sum_{i=1}^{n} P_{i}\right)^{2}+\sum_{i=1}^{n}\left(V_{i}-\bar{V}_{1}\right)^{2}
$$

$\eta$, represents the variations in the utility forecasts. In this thesis three different utility forecast are considered for case study. The constructed multi-objective function is evaluated to be a not strictly convex problem and to find better solutions, the following constraints are used to border its variations.

\subsection{Constraints}

The following nodal power constraints are modeled to follow the Kirchhoff's Current Law (KVL). The following figure is used to illustrate the power injection to a generalized node.

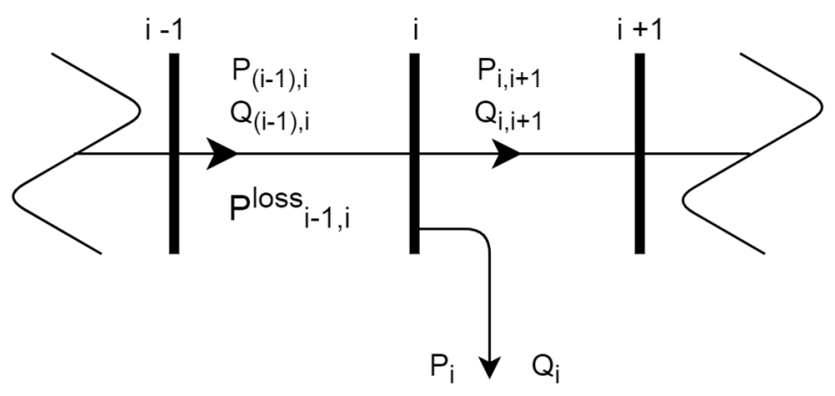

Figure 3.1: Feeder sections connected to node i [11]

\section{a. Real Power Flow}

Power flowing into the node $i$, can be computed as follows. The power loss considered for the line segment $i-1$ to $i$.

$$
P_{i}=P_{i, i-1}-P_{i-1, i}^{l o s s}-P_{i, i+1}
$$

Where, $\mathrm{i}=1 \ldots \mathrm{N}$ 


\section{b. Reactive Power Flow}

Power flowing into the node $i$, can be computed as follows. The power loss considered for the line segment $i-1$ to $i$.

$$
\mathrm{Q}_{\mathrm{i}}=\mathrm{Q}_{\mathrm{i}, \mathrm{i}-1}-\mathrm{Q}_{\mathrm{i}, \mathrm{i}+1}
$$

Where, $\mathrm{i}=1 \ldots \mathrm{N}$

c. Power Factor

$$
\mathrm{PF}_{\min } \leq \mathrm{Cos} \alpha_{\mathrm{i}} \leq \mathrm{PF}_{\max }
$$

The power factor at each node $i$ is kept within the operating conditions to deliver a reliable power supply to the consumers. Although it is considered to be the responsibility of the commercial consumers to maintain power factor within the rated limits, in this thesis we have passed the responsibility to the residential customers as well. A good power factor is a sign of a good power supply as well as the quality of the utility.

\section{d. Voltage Limits}

The nodal voltages are kept within the American National Standards Institute (ANSI) [12] voltage limits to ensure that system operating conditions are met. Since it's the responsibility of the Utility to supply power at the rated voltage, they would ensure that these conditions are met despite the fact of the consumer's irregular behavior.

$$
\mathrm{V}_{\min } \leq \mathrm{V}_{\mathrm{i}} \leq \mathrm{V}_{\max }
$$


Also, the maximum and minimum real power and reactive power variation at each node are limited by a percentage of its forecasted power demand. This is to ensure that the customer forecast converges around the utility forecast and is not too far from it when it is optimized.

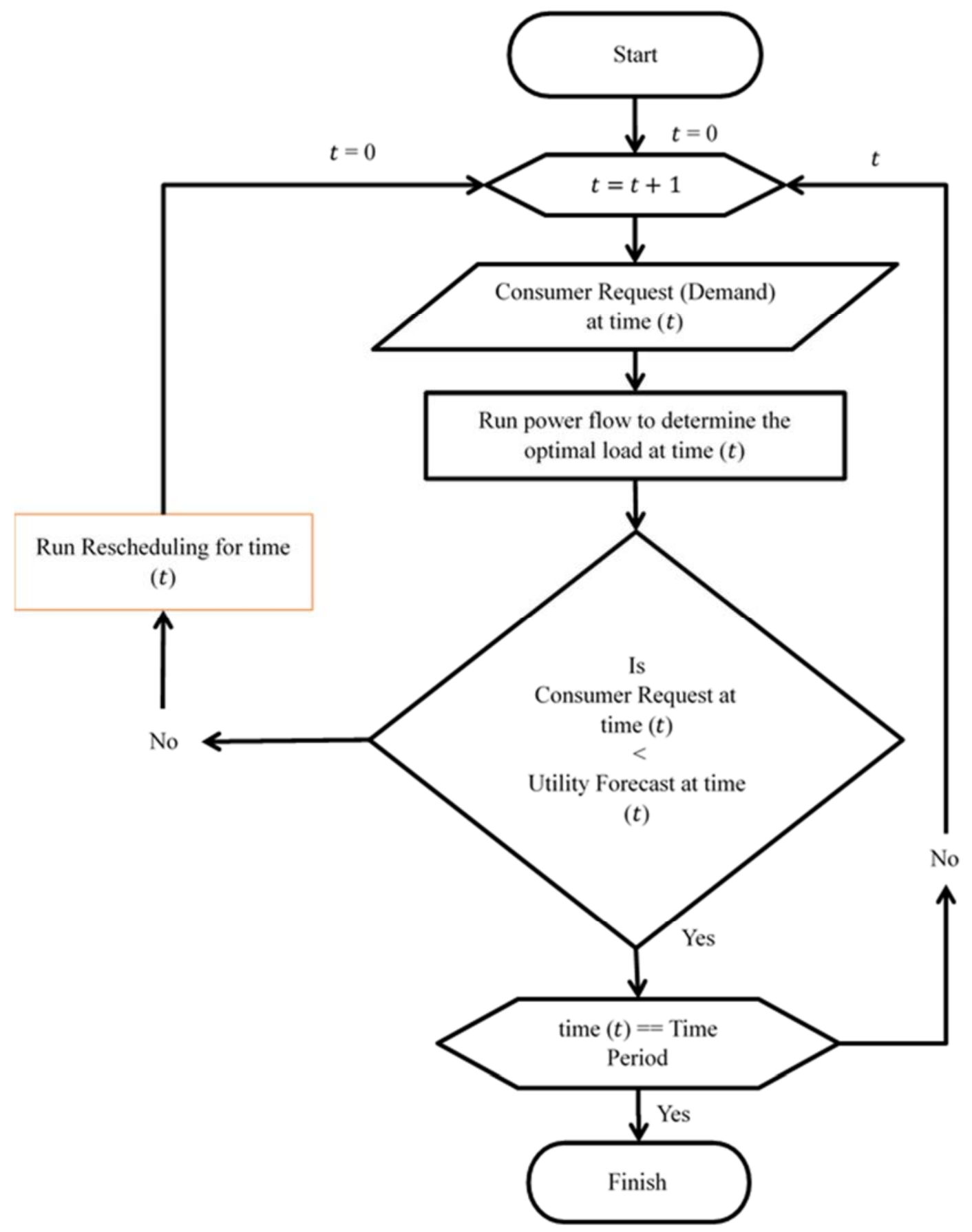

Figure 4.2: Aggregator level process 
The above flowchart describes the process of a simulation for time $t$. The process starts with picking up the aggregated nodal power from the consumer demand forecast. The optimization algorithm starts to find accurate nodal power supplied to minimize the deviation in the utility load forecast and the consumer demand forecast as well as minimize the nodal voltage deviation. Once the constraints are satisfied, the simulation outputs power for each node and will compare with its aggregated consumer demand forecast power to ensure that at time $t$, the substation could meet the demand.

The output power from the optimization, as mentioned before, will always try to meet the utility load forecast because of the objective function conditions. If the simulation could not meet the demand, in the second step of this process, appliance rescheduling starts. When it finishes, the simulation will start from the beginning. This is to ensure that every time slot is optimized for the given distribution system conditions once the appliance rescheduling has distributed among the number of the time slot. 


\section{CHAPTER 5}

\section{NUMERICAL ANALYSIS}

IEEE 4 bus radial distribution feeder with a rated voltage of $4.16 \mathrm{kV}$ line to line is used for numerical analysis for this proposed model [13]. It is assumed that each node is controlled by a local aggregator and node 2 to 4 are modeled with the consumers considering line impedances according to table 10. This radial distribution feeder is modeled with the assumption of unidirectional power flow and the following line information is taken from the IEEE 4 bus test feeder data available on [13].

TABLE 10

LINE IMPEDANCE DATA

\begin{tabular}{|c|c|c|c|}
\hline & 1 & 2 & 3 \\
\hline $\mathrm{z}_{\mathrm{ij}}$ & $0.087+\mathrm{j} 0.20$ & $0.088+\mathrm{j} 0.20$ & $0.13+\mathrm{j} 0.30$ \\
\hline
\end{tabular}

However, the following test feeder is modified by neglecting the local substation transformer.

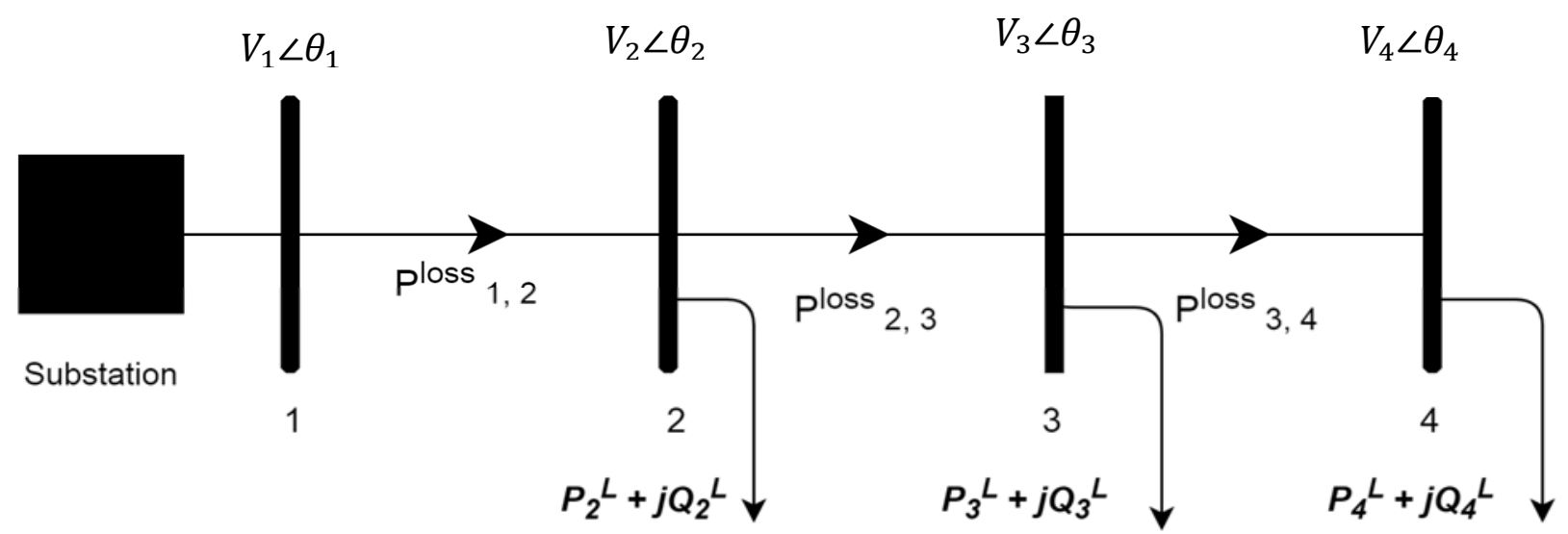

Figure 4.1: IEEE four node distribution test feeder [13] 
The following table shows optimization boundaries and their initial states. The voltage limits are preferred to be around 1 p.u. Since the purpose of this model is to analyze the impact of real power on the system, the variation of real power is limited by $\pm 0.3 \%$ of consumer forecast data for each time. Therefore, the reactive power boundaries are loosened up to support hard constraints such as power factor and voltage deviation.

TABLE 11

OPTIMIZATION LIMITS AND DATA

\begin{tabular}{|c|c|c|c|c|}
\hline Variable & Type & $\begin{array}{c}\text { Lower bound (per } \\
\text { unit) }\end{array}$ & $\begin{array}{c}\text { Upper Bound } \\
\text { (per unit) }\end{array}$ & $\begin{array}{c}\text { Initial state (per } \\
\text { unit) }\end{array}$ \\
\hline $\mathrm{V}_{i}$ & Node Voltage & 0.9 & 1.1 & 1 \\
\hline$\theta_{i}$ & Node Angle & -1 & 1 & 0 \\
\hline $\mathrm{P}_{i}$ & Real Power & $\begin{array}{c}\text { Consumer } \\
\text { Forecast } \times 0.7 \%\end{array}$ & $\begin{array}{c}\text { Consumer } \\
\text { Forecast } \times 1.3 \%\end{array}$ & Forecast \\
\hline $\mathrm{Q}_{i}$ & Reactive Power & $\begin{array}{c}\text { Consumer } \\
\text { Forecast } \times 0.01 \%\end{array}$ & $\begin{array}{c}\text { Consumer } \\
\text { Forecast } \times 2.6 \%\end{array}$ & Forecast \\
\hline $\mathrm{PF}$ & Power Factor & 0.8 & 1 & 1 \\
\hline
\end{tabular}

Using the "fmincon" function in MATLAB optimization toolbox, the optimal solutions that satisfy the distribution system requirements are obtained for a 24-hour period [14]. The following pseudocode shown in figure 5.2 shows the basic steps that need for an objective function optimization. The nonlinear constraint function at line 25 and rescheduling programs at lines, 31 , 33 and 35 for each node are called separately at respective lines by the program. 


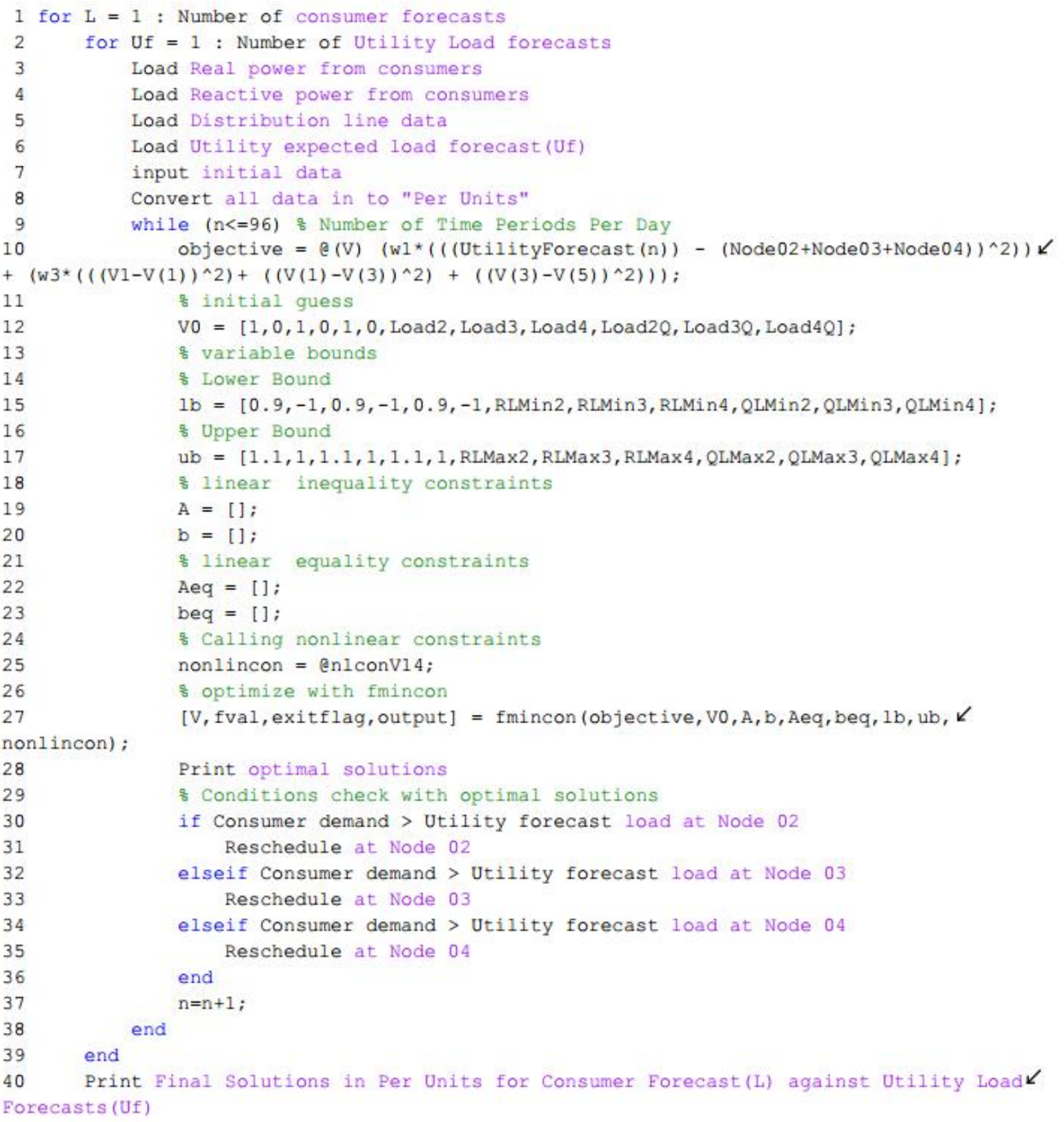

Figure 5.2: Optimization using built-in fmincon function 
The following analysis is simulated, and the results show the voltage deviation and distribution feeder power factors after rescheduling of consumer loads for 30 consumer forecasts as shown in figure 5.3.

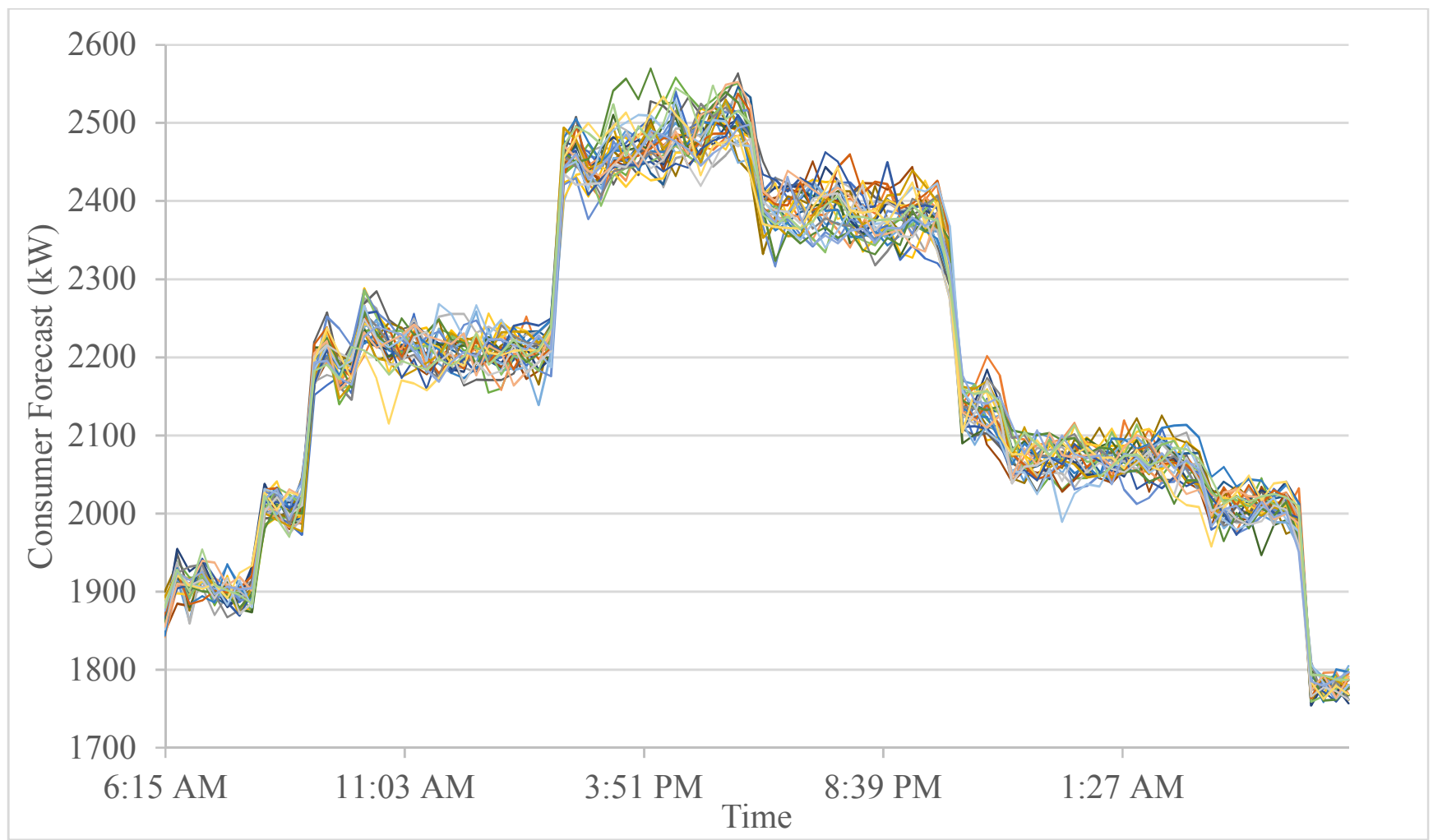

Figure 5.3: 30 Consumer Demand Forecasts

The following figure 5.4 shows the utility forecasts. The slightly varied three-different utility forecast were considered to evaluate consumer load rescheduling as discussed. 


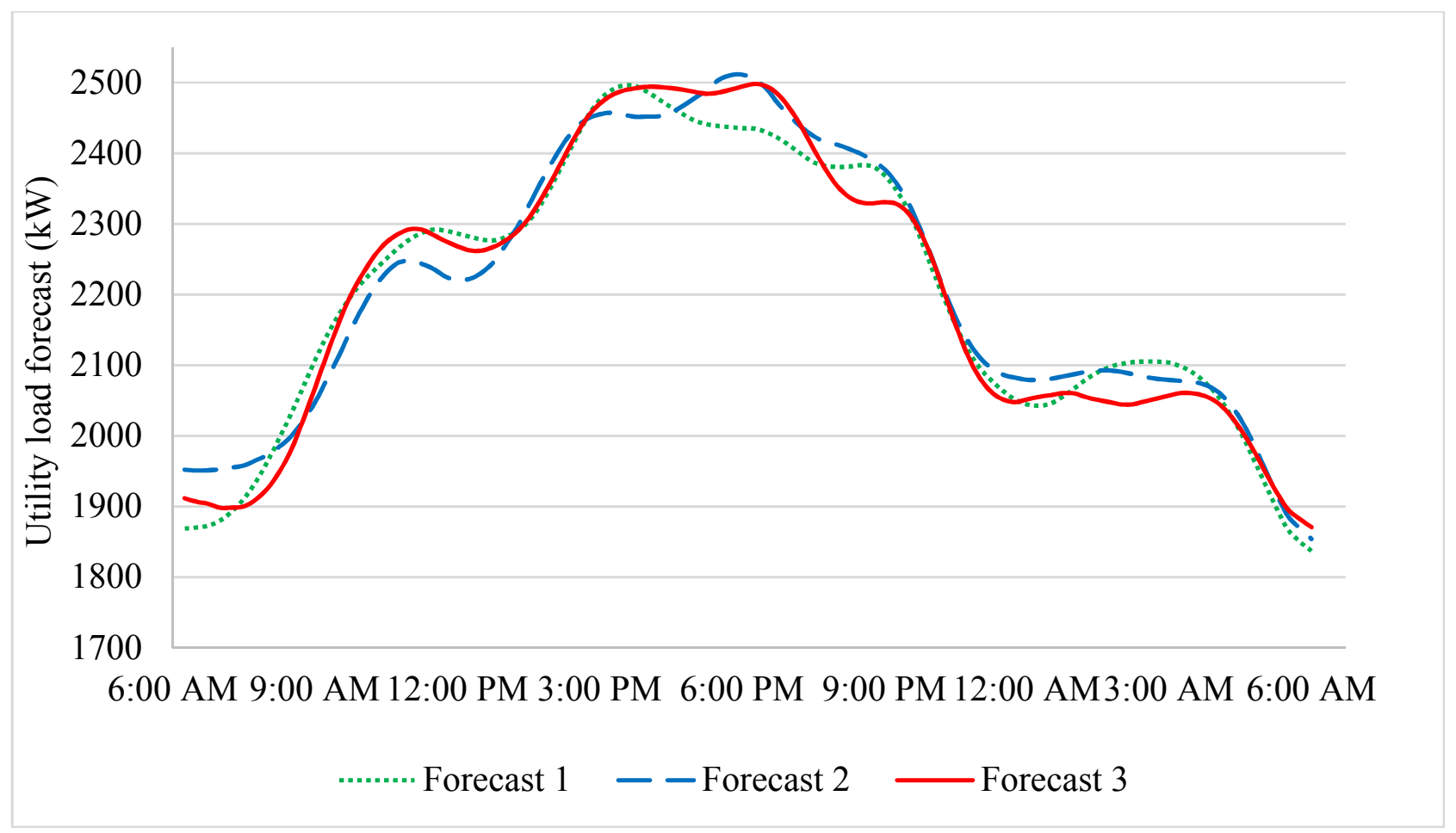

Figure 5.4: Three utility load forecasts

The simulation results have analyzed further by categorizing them into two areas. Frist, how the rescheduling has benefitted the consumers and second, how it has benefitted the utility by at distribution level. This was the motivation to this thesis and two of the objectives we considered to identify the benefit to the consumers as well as the utility.

As for the consumers benefit, their satisfaction is considered by evaluating the number of appliances that have been rescheduled by the DR program. Table 12 shows the average number of consumer appliances rescheduled for each utility forecast for 30 consumer forecasts with the same number of appliances. The appliances types, electric iron, and random appliances have shown be have been rescheduled more than the other appliances for every utility forecasts. The reason is that the electric iron and the random appliance categories both have lower power requirements. Hence, they need to be scheduled more than one time to reduce significant power reduction and to archive, 
utility expected load forecast profile. Also, they are scheduled to operate at the wider time period. Therefore, the rescheduling process has selected these two appliances more times than the others.

TABLE 12

NUMBER OF RESCHEDULED APPLIANCES FOR UTILITY FORECAST 01

\begin{tabular}{|c|c|c|c|c|c|c|}
\hline \multirow{5}{*}{ Load Type } & \multicolumn{6}{|c|}{ For utility forecast 1} \\
\hline & \multicolumn{2}{|c|}{ Node 02} & \multicolumn{2}{|c|}{ Node 03} & \multicolumn{2}{|c|}{ Node 04} \\
\hline & \multicolumn{6}{|c|}{ Total Participants at each node } \\
\hline & \multicolumn{2}{|c|}{ Out of 2000 Consumers } & \multicolumn{2}{|c|}{ Out of 1700 Consumers } & \multicolumn{2}{|c|}{ Out of 2300 Consumers } \\
\hline & $\begin{array}{c}\text { Total } \\
\text { Participants }\end{array}$ & Rescheduled & $\begin{array}{c}\text { Total } \\
\text { Participants }\end{array}$ & Rescheduled & $\begin{array}{c}\text { Total } \\
\text { Participants }\end{array}$ & Rescheduled \\
\hline Electric Iron & 1500 & 219 & 1500 & 157 & 1300 & 268 \\
\hline $\begin{array}{l}\text { Programmable } \\
\text { Dishwasher }\end{array}$ & 1000 & 32 & 600 & 18 & 800 & 74 \\
\hline $\begin{array}{l}\text { Washer and } \\
\text { Dyer }\end{array}$ & 1200 & 57 & 900 & 23 & 1200 & 60 \\
\hline $\begin{array}{c}\text { Random } \\
\text { appliance }\end{array}$ & 2000 & 263 & 1700 & 215 & 2300 & 313 \\
\hline $\begin{array}{l}\text { Electric } \\
\text { Vehicle }\end{array}$ & 35 & 6 & 35 & 5 & 20 & 4 \\
\hline
\end{tabular}


TABLE 13

NUMBER OF RESCHEDULED APPLIANCES FOR UTILITY FORECAST 02

\begin{tabular}{|c|c|c|c|c|c|c|}
\hline \multirow{5}{*}{ Load Type } & \multicolumn{6}{|c|}{ For utility forecast 2} \\
\hline & \multicolumn{2}{|c|}{ Node 02} & \multicolumn{2}{|c|}{ Node 03} & \multicolumn{2}{|c|}{ Node 04} \\
\hline & \multicolumn{6}{|c|}{ Total Participants at each node } \\
\hline & \multicolumn{2}{|c|}{ Out of 2000 Consumers } & \multicolumn{2}{|c|}{ Out of 1700 Consumers } & \multicolumn{2}{|c|}{ Out of 2300 Consumers } \\
\hline & $\begin{array}{c}\text { Total } \\
\text { Participants }\end{array}$ & Rescheduled & $\begin{array}{c}\text { Total } \\
\text { Participants }\end{array}$ & Rescheduled & $\begin{array}{c}\text { Total } \\
\text { Participants }\end{array}$ & Rescheduled \\
\hline Electric Iron & 1500 & 165 & 1500 & 145 & 1300 & 211 \\
\hline $\begin{array}{c}\text { Programmable } \\
\text { Dishwasher }\end{array}$ & 1000 & 18 & 600 & 6 & 800 & 33 \\
\hline $\begin{array}{c}\text { Washer and } \\
\text { Dyer }\end{array}$ & 1200 & 35 & 900 & 17 & 1200 & 44 \\
\hline $\begin{array}{c}\text { Random } \\
\text { appliance }\end{array}$ & 2000 & 197 & 1700 & 181 & 2300 & 224 \\
\hline $\begin{array}{l}\text { Electric } \\
\text { Vehicle }\end{array}$ & 35 & 4 & 35 & 3 & 20 & 3 \\
\hline
\end{tabular}

TABLE 14

NUMBER OF RESCHEDULED APPLIANCES FOR UTILITY FORECAST 03

\begin{tabular}{|c|ccc|c|c|c|}
\hline \multirow{2}{*}{ Load Type } & \multicolumn{5}{|c|}{ Node 02 } & \multicolumn{2}{c|}{ Node 03 } & \multicolumn{2}{c|}{ Node 04 } \\
\cline { 2 - 7 } & \multicolumn{5}{|c|}{ Total Participants at each node } \\
\cline { 2 - 7 } & $\begin{array}{c}\text { Out of 2000 Consumers } \\
\text { Total }\end{array}$ & $\begin{array}{c}\text { Out of 1700 Consumers } \\
\text { Participants }\end{array}$ & Out of 2300 Consumers \\
\hline Electric Iron & 1500 & 221 & 1500 & 146 & $\begin{array}{c}\text { Total } \\
\text { Participants }\end{array}$ & Rescheduled \\
\hline $\begin{array}{c}\text { Programmable } \\
\text { Dishwasher }\end{array}$ & 1000 & 30 & 600 & 6 & 800 & 78 \\
\hline $\begin{array}{c}\text { Washer and } \\
\text { Dyer }\end{array}$ & 1200 & 43 & 900 & 23 & 1200 & 55 \\
\hline $\begin{array}{c}\text { Random } \\
\text { appliance }\end{array}$ & 2000 & 279 & 1700 & 208 & 2300 & 330 \\
\hline $\begin{array}{c}\text { Electric } \\
\text { Vehicle }\end{array}$ & 35 & 8 & 35 & 6 & 20 & 7 \\
\hline
\end{tabular}


The benefit to the utility at distribution level is considered by evaluating the voltage deviation and how the rescheduled consumer forecast demand profile is following the utility expected load profile. Also, by rescheduling the consumer appliance load, this thesis considered to keep the power factor at each node within the limits. Finally, after rescheduling the times that consumer demand is higher than the utility expected load, is evaluated by calculating the energy over forecasted to be considered in the utility's next day generation.

The average voltage deviation before and after rescheduling at each node, for each utility forecasts, are presented below. Figures 5.5 shows without rescheduling while figure 5.6 shows the node voltages after rescheduling for utility forecast 01 . The rescheduled nodal voltages are kept close to 1.0 per unit and within the limits of 0.9 and 1.1.

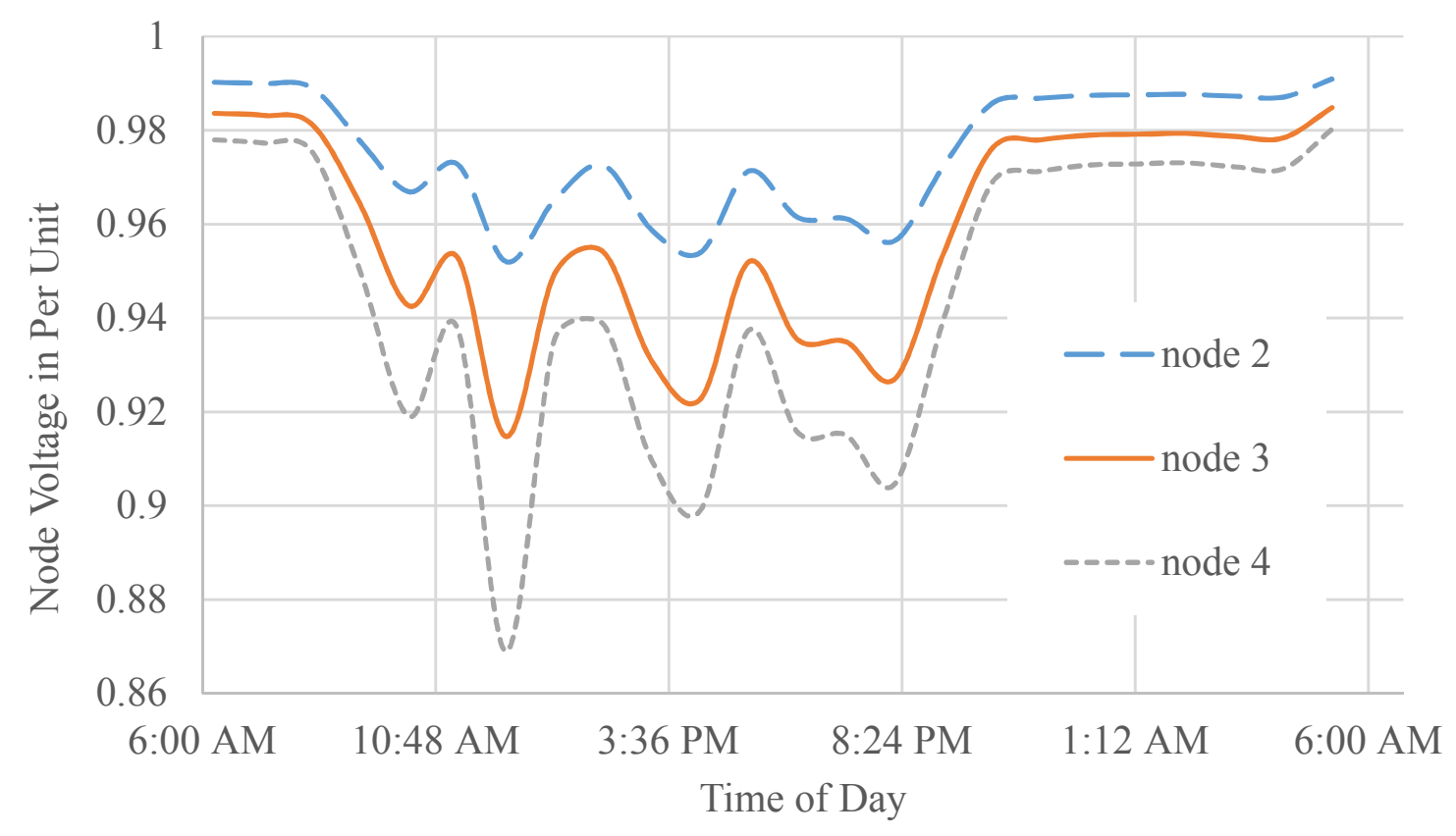

Figure 5.5: Node voltages for utility forecast 01 without reschedule 


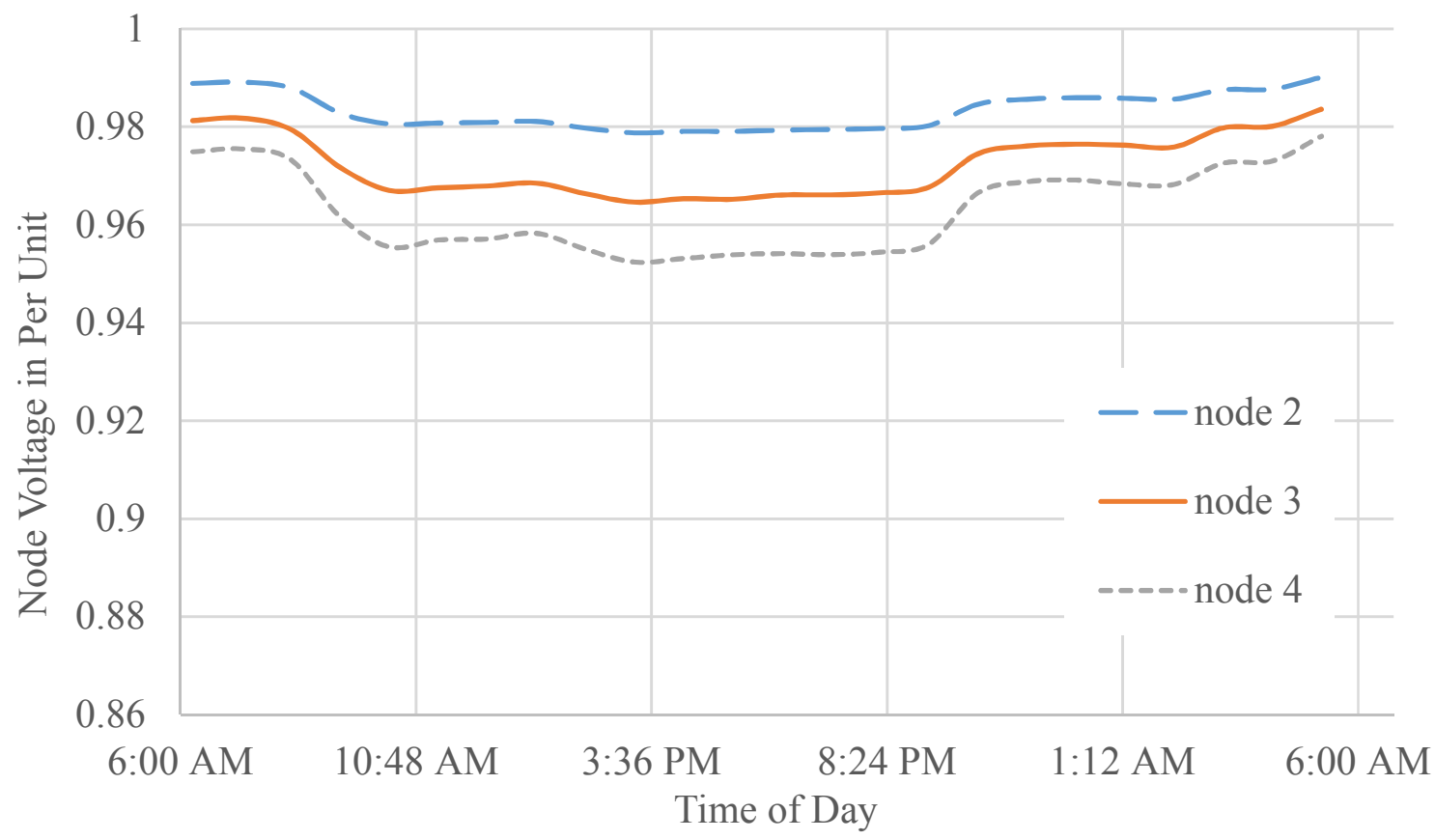

Figure 5.6: Node voltages for utility forecast 01 with reschedule

Voltages for utility forecast 02 without rescheduling is shown in figure 5.7 and with rescheduling is shown in figure 5.8 below.

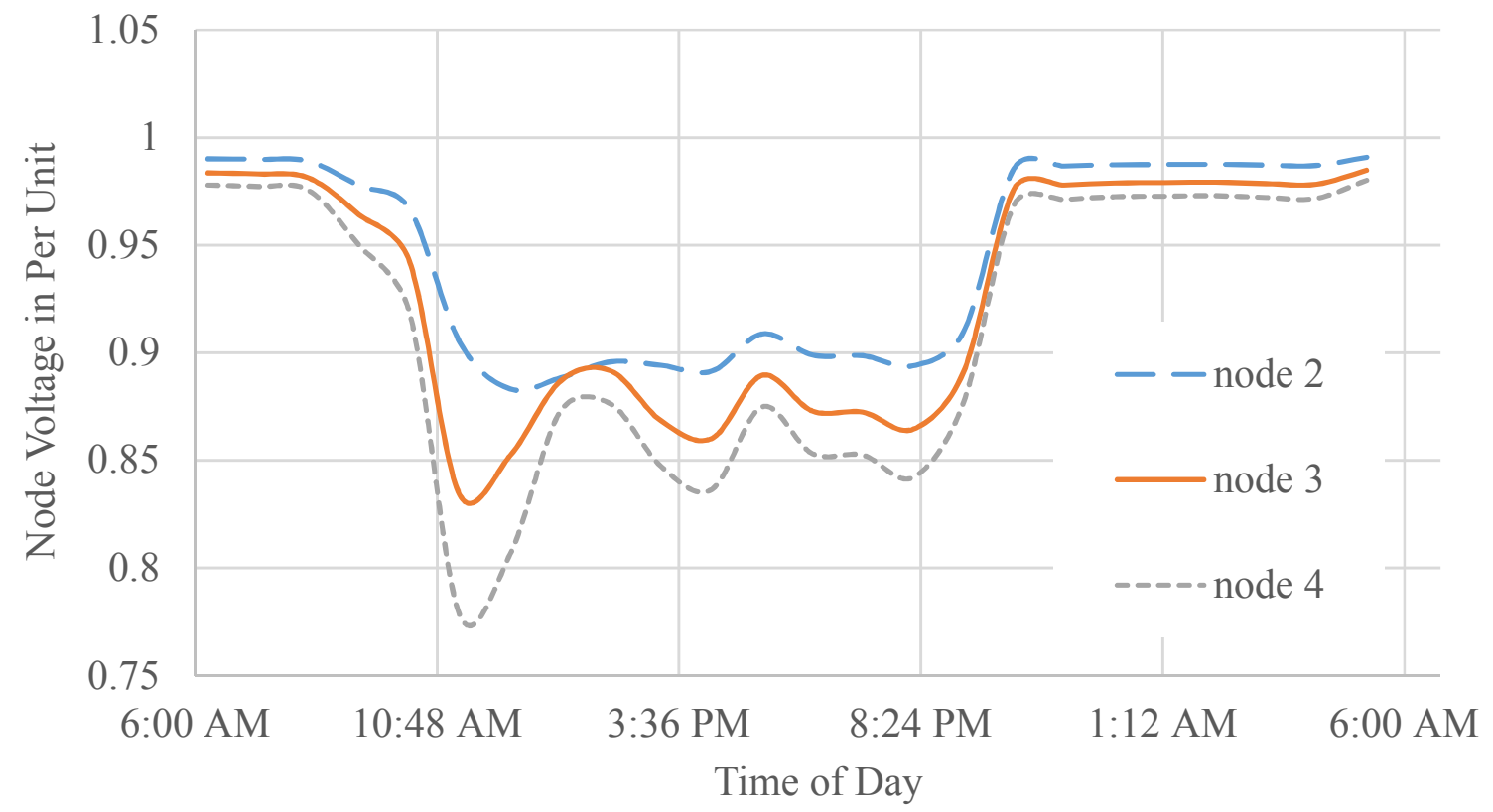

Figure 5.7: Node voltages for utility forecast 02 without reschedule 


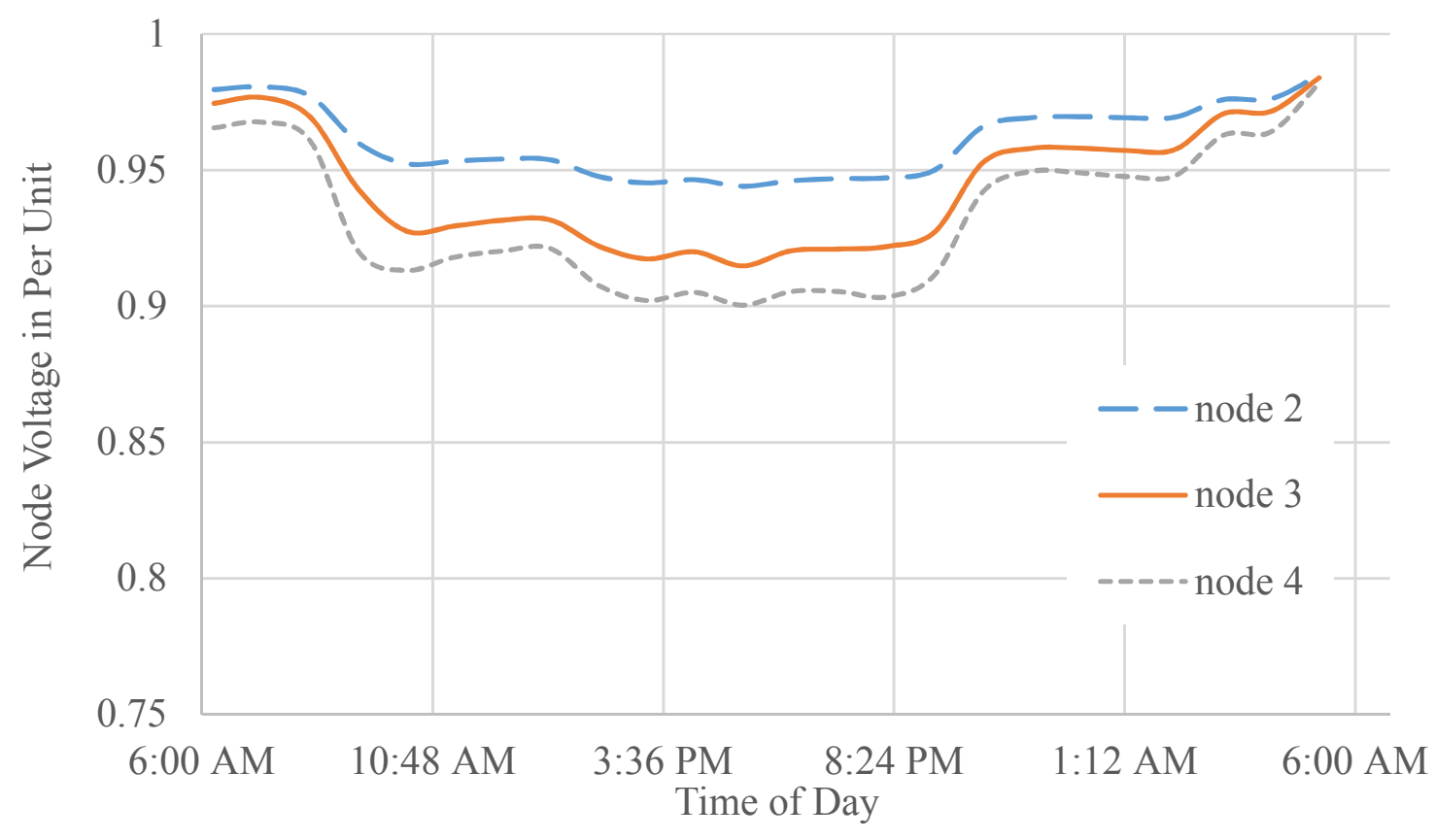

Figure 5.8: Node voltages for utility forecast 02 with reschedule

Voltages for utility forecast 03 without rescheduling is shown in figure 5.9 and with rescheduling is shown in figure 5.10 below.

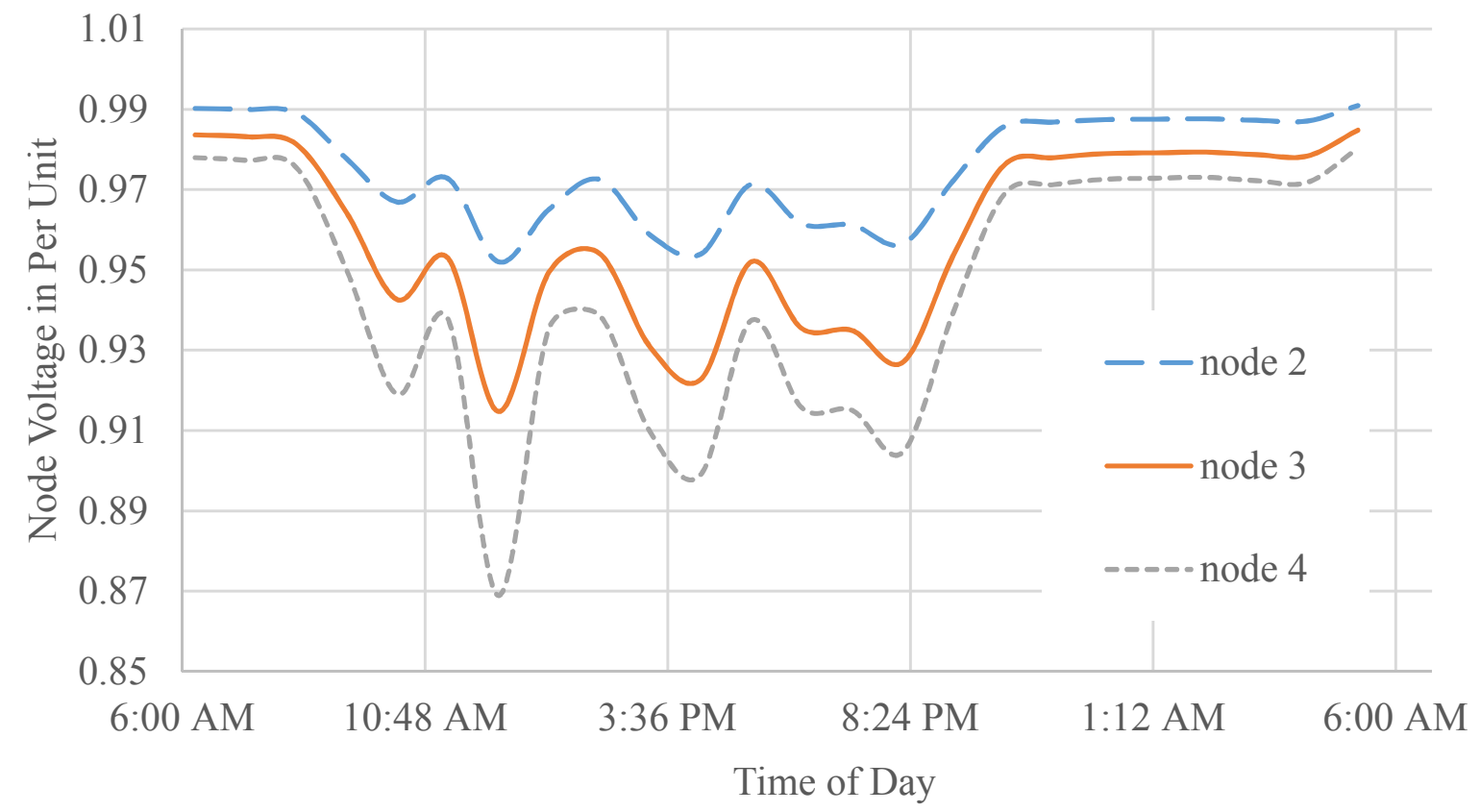

Figure 5.9: Node voltages for utility forecast 03 without reschedule 


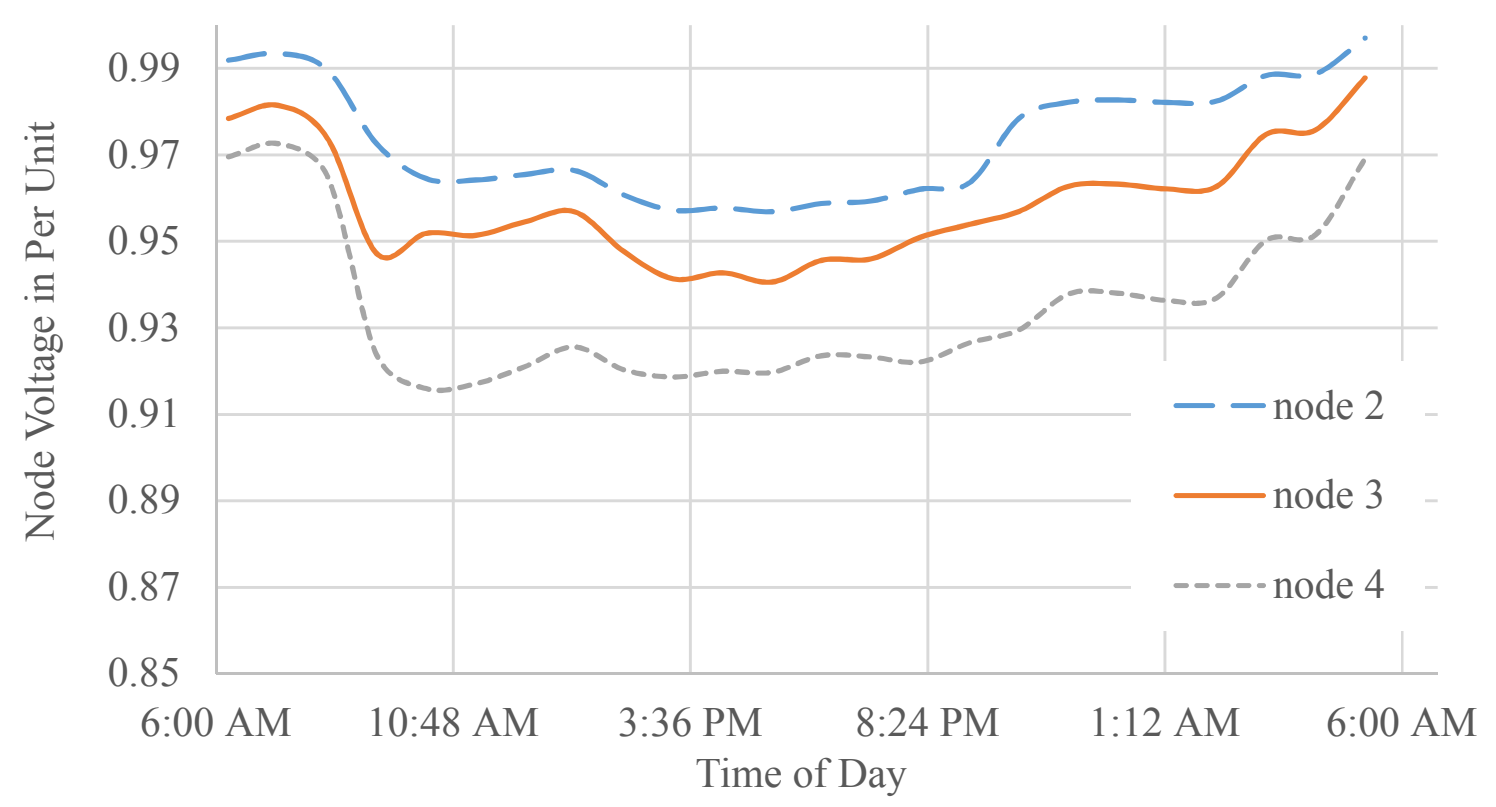

Figure 5.10: Node voltages for utility forecast 03 with reschedule

The following figure 5.11 shows the average consumer forecast based on 30 different consumer forecasts and then the average demand rescheduled for every 30 simulations for the historical Utility forecast 01 . The figures 5.12 and 5.13 also shows the average consumer demand rescheduled profile for the Utility historical forecasts 02 and 03 respectively. 


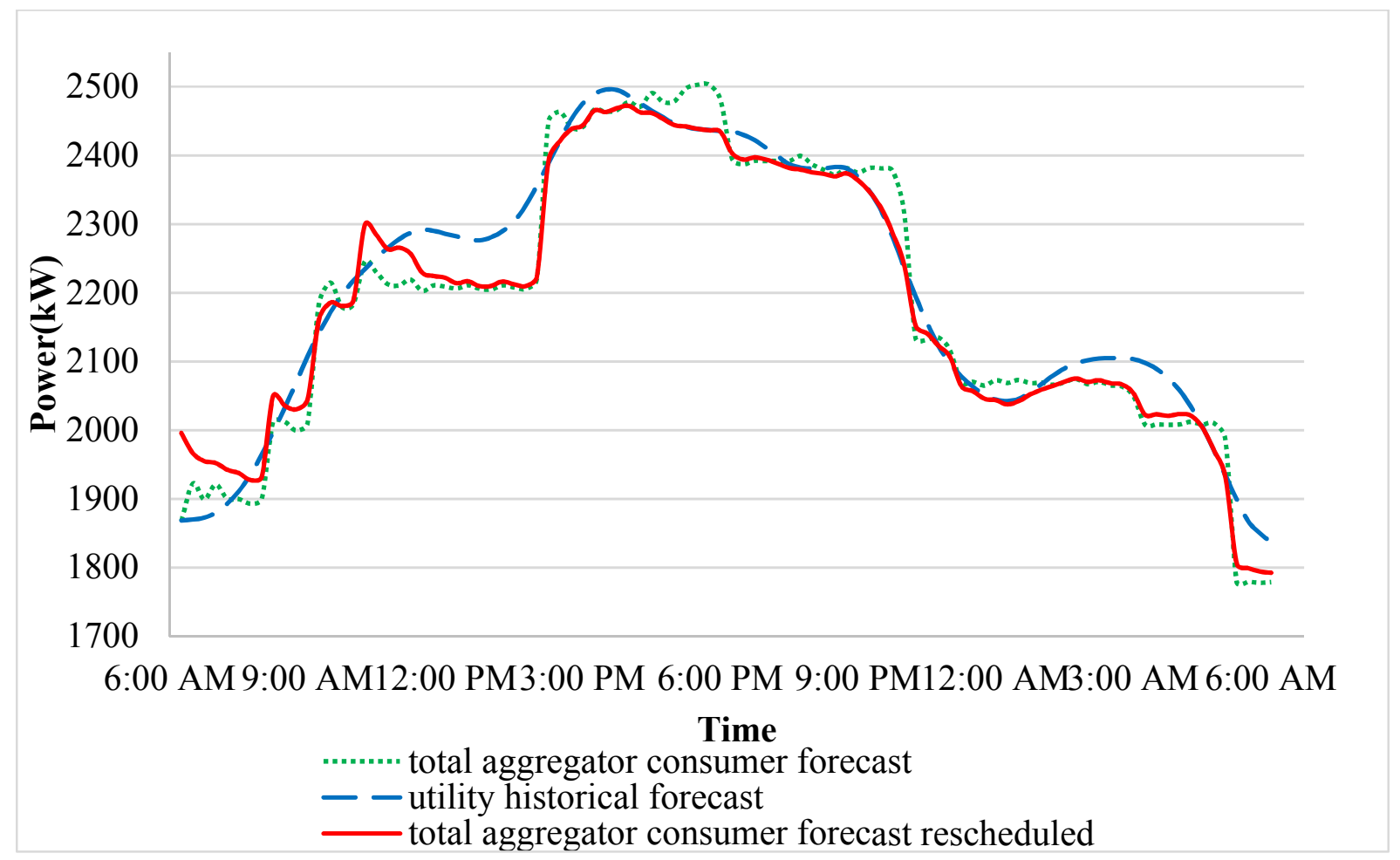

Figure 5.11: Consumer rescheduled demand for utility forecast 01

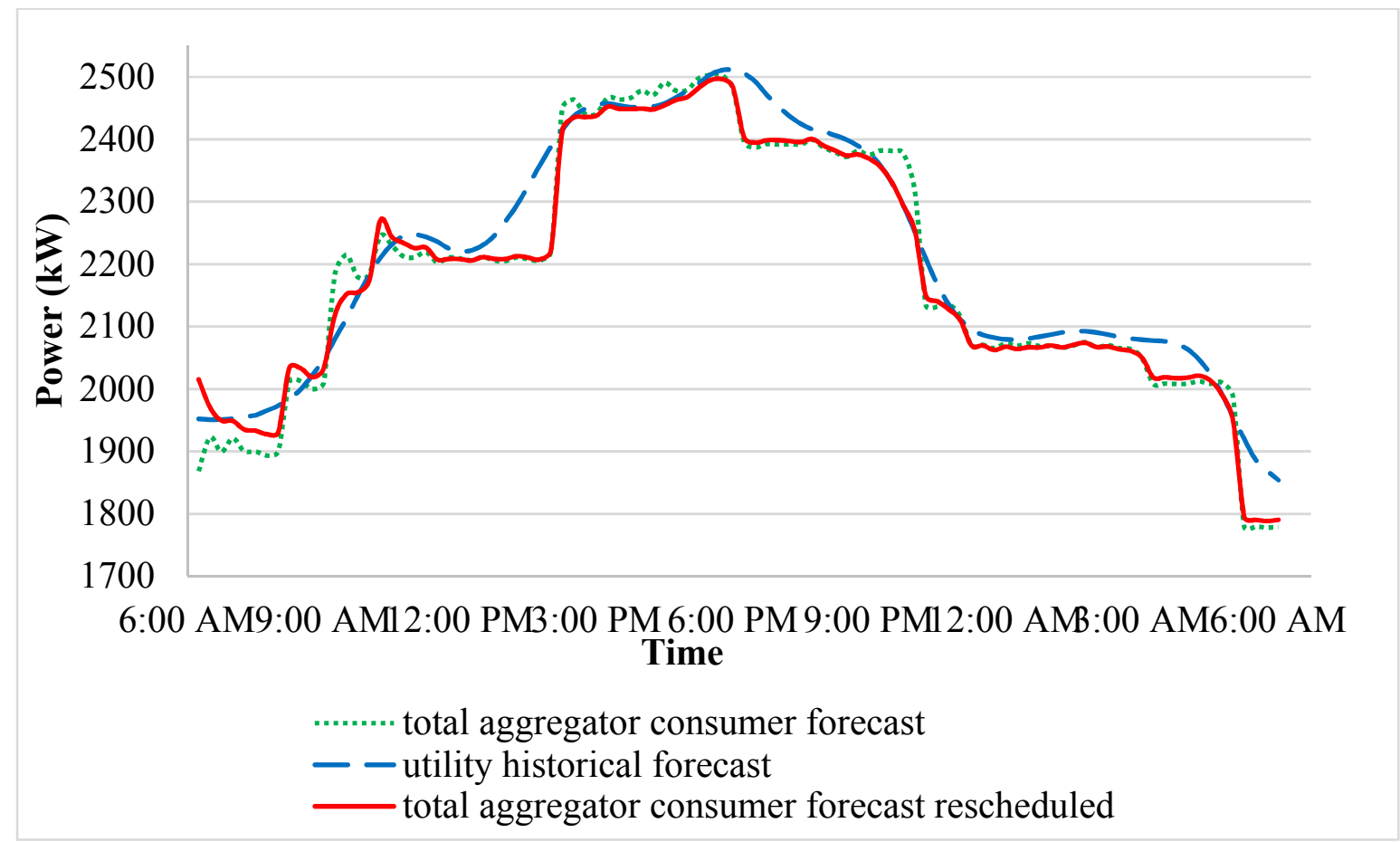

Figure 5.12: Consumer rescheduled demand for utility forecast 02 


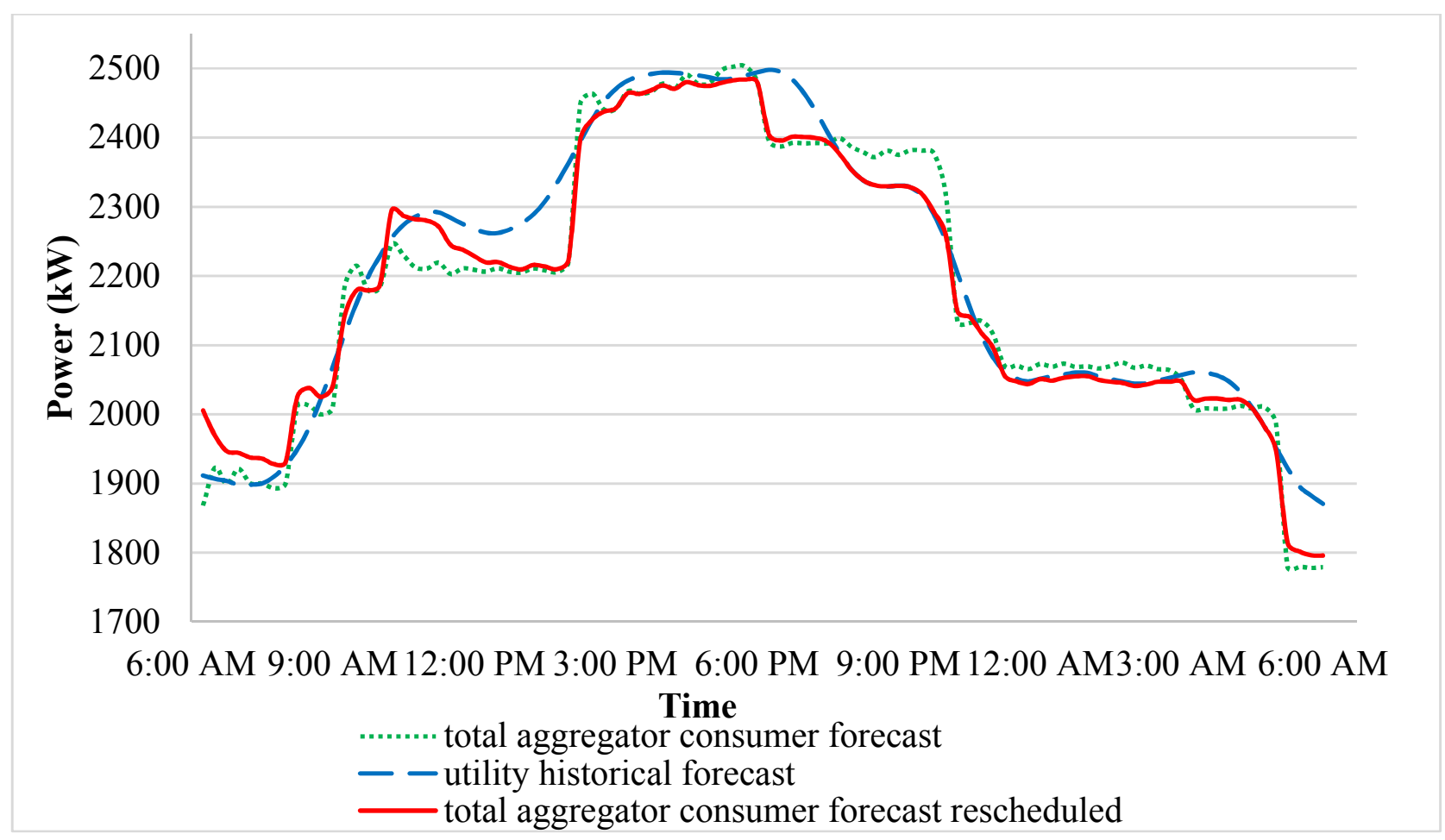

Figure 5.13: Consumer rescheduled demand for utility forecast 03

The figure 5.14 illustrates the average number of times the Utility load forecast was unable to serve the consumer demand forecast, after its being rescheduled. These times must be wellthought-out by the utility in order to plan their generation for the forecasted day to supply their customers. Closer and beyond the utility expected load profile projected, around the consumer demand forecast profile, the faster it converges around the utility load forecast once the rescheduling has started. This also enables the simulation to archive lesser number of times that that consumer load profile is going beyond the Utility load forecast profile. The utility load forecast 02 shows a higher number of times than other load forecasts, while forecast 01 shows the minimum number of times that the rescheduling has unable to serve consumer demand. It should worth to 
remember that each of these simulations has completed satisfying the distribution level requirements.

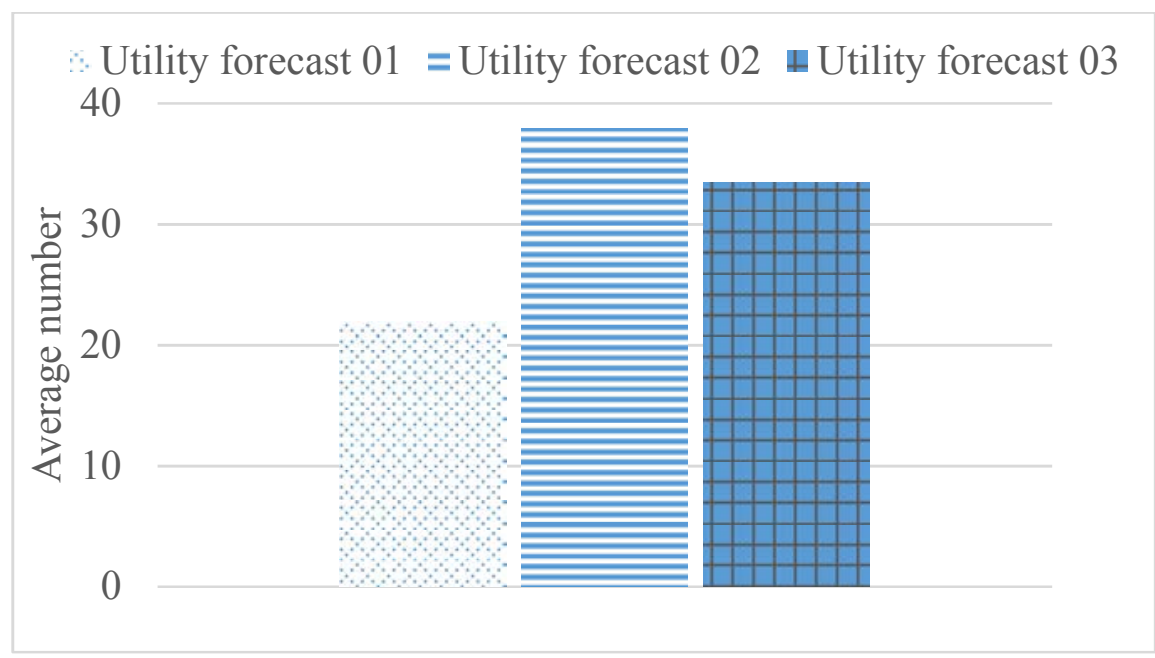

Figure 5.14: Average number of times that the rescheduled forecast higher than utility forecast

Because of that, the figure 5.15 box plot graphs for corresponding Utility load forecasts, shows the average consumer energy over forecasted and the whiskers show the maximum and minimum energy that could not serve during each corresponding Utility forecast 01,02 and 03.

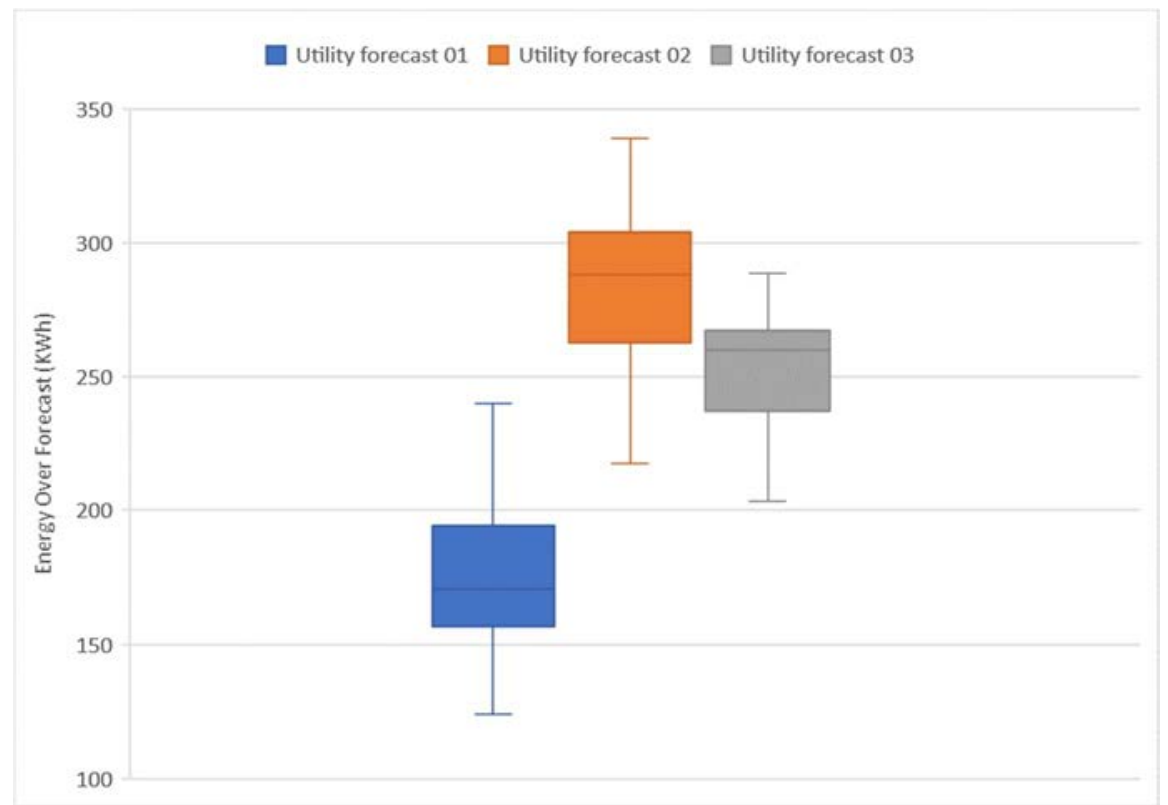

Figure 5.15: Average Energy Usage Over forecast 
On average for simulations ran for utility forecast 01 , shows an average of $170 \mathrm{kWh}$ of energy not being able to supply, with a maximum of $240 \mathrm{kWh}$ and a minimum of $125 \mathrm{kWh}$ energy not being able to serve during two of its 30 simulations. The maximum of an average of energy not being able to serve is when the 30 simulations ran for the utility forecast 02 with an average of around $290 \mathrm{kWh}$. It had a maximum of $340 \mathrm{kWh}$ energy not being able to serve according to the utility forecast 02 . The simulations ran for Utility forecast 03 , shows the average $260 \mathrm{kWh}$ energy which places between the Utility forecast 01 and 03 .

These utility forecasts profiles indicate that need of a better accurate model to predict close to the Consumer forecast for their planning for the next day. As mentioned before, the closer the utility load forecast gets, the minimum number of chances that the reschedule of consumer appliances must be done and it benefits the consumers at large.

The figure 5.16 to 5.18 shows the average power factor results for three utility forecasts.

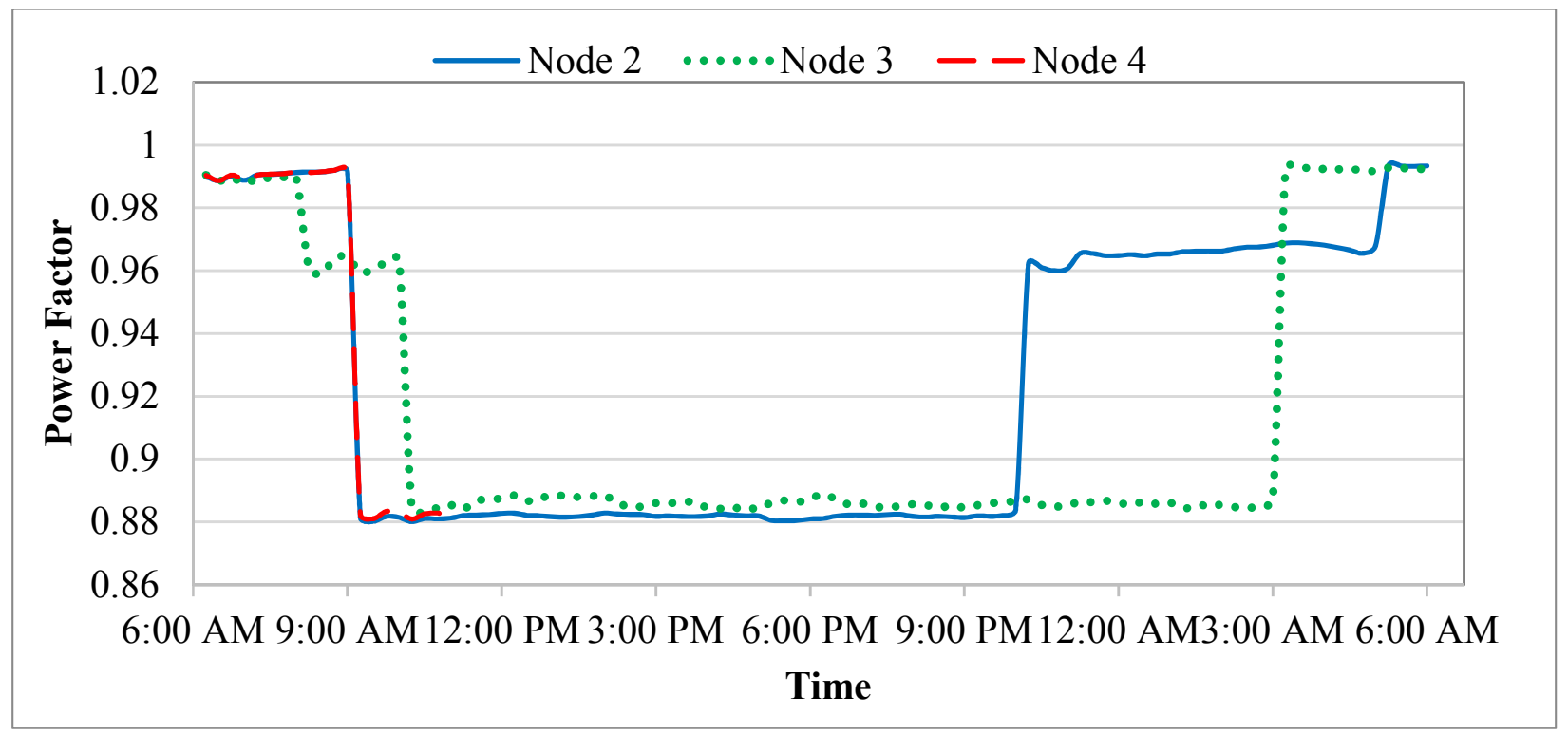

Figure 5.16: Power factor for Utility Forecast 01 


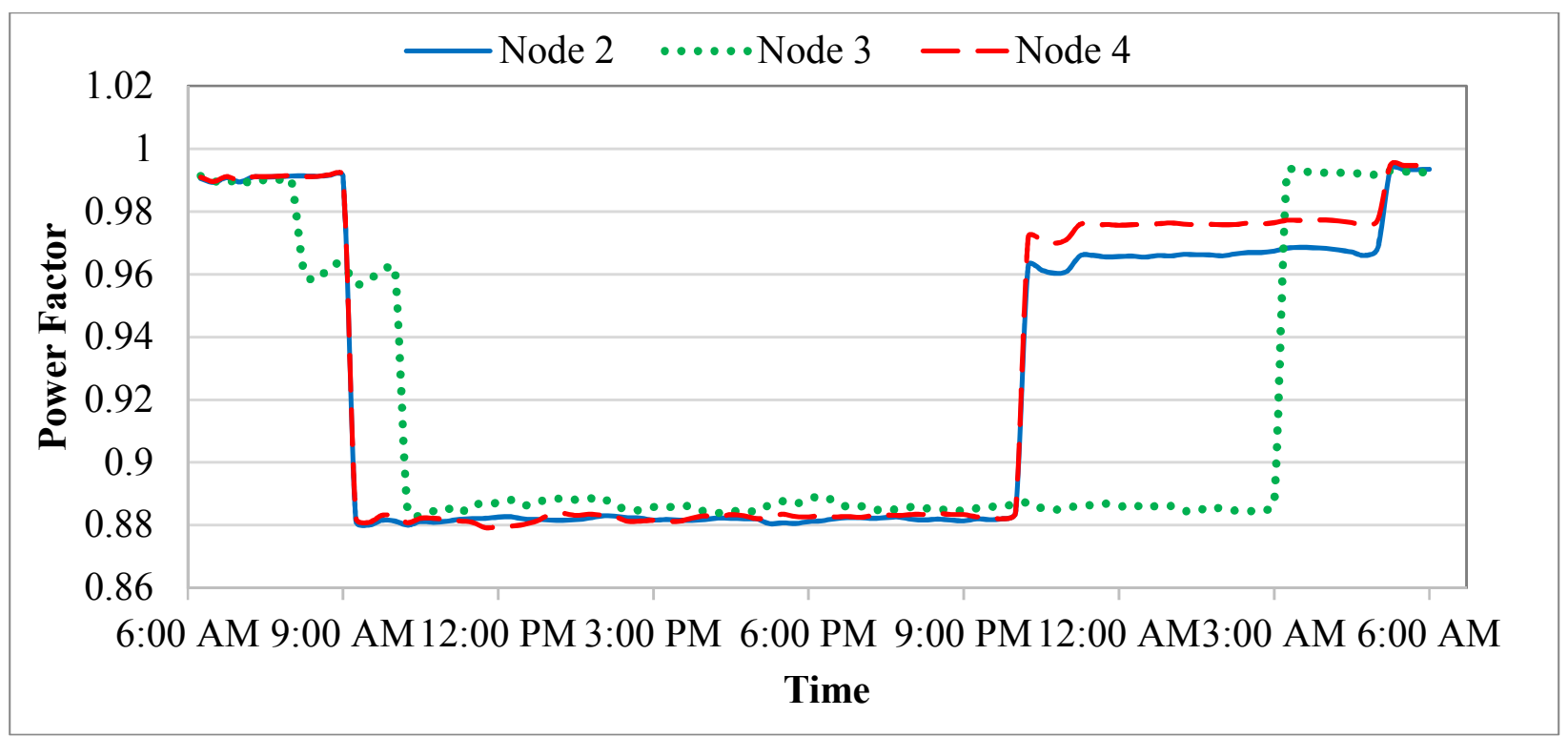

Figure 5.17: Power factor for Utility Forecast 02

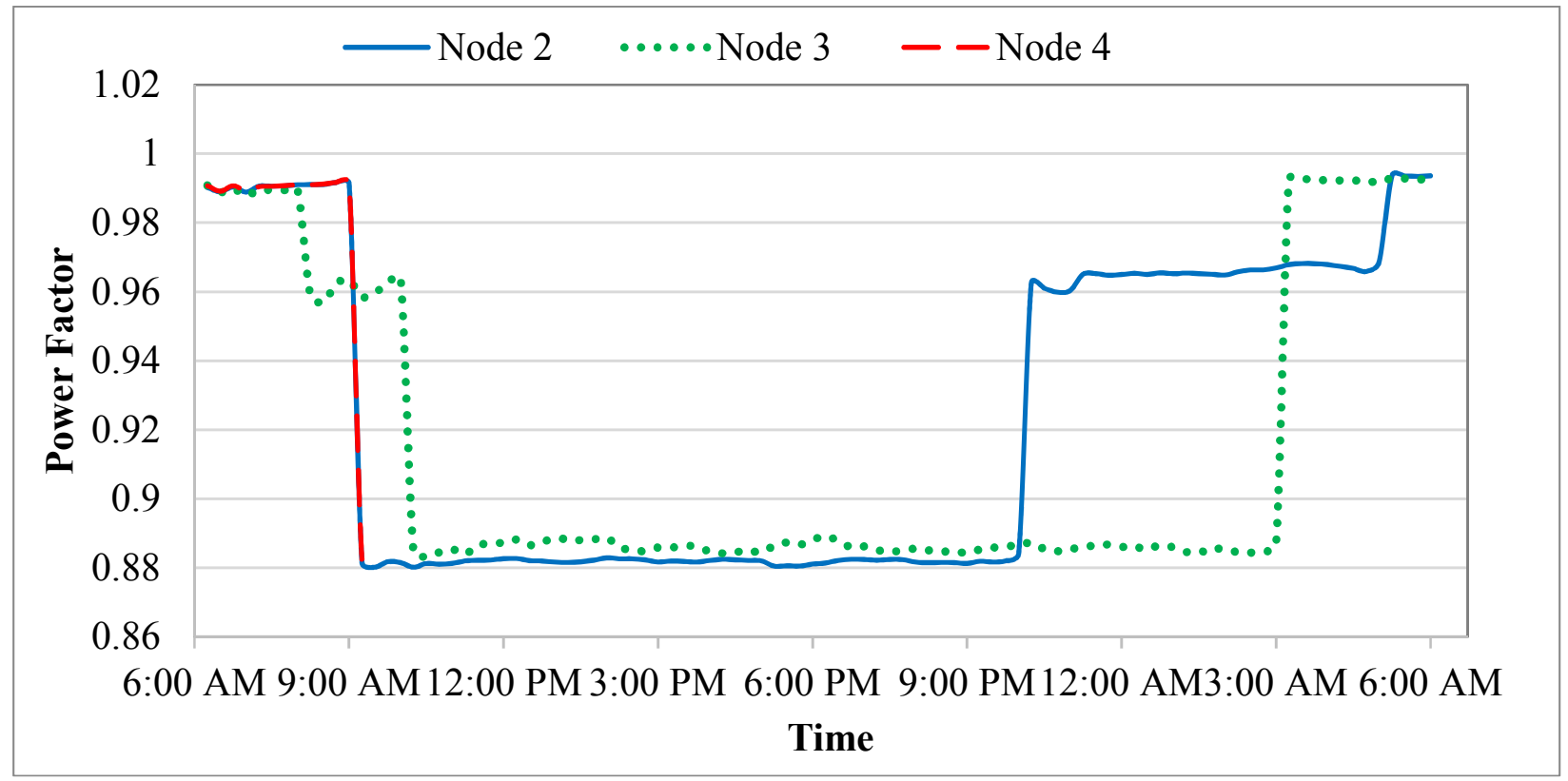

Figure 5.18: Power factor for Utility Forecast 03

Since the number of appliances is not changed for this model, and also power factors are used as hard constraints for the objective faction, the graphs show a little variation. However, the 
power factor values are within the range of 0.8 and 1 . Being the results within the expected range or better gives an added value to this research. 


\section{CHAPTER 6}

\section{CONCLUSION AND FUTURE WORKS}

\subsection{Conclusion}

This thesis addresses the possibility of rescheduling consumer appliances at peak loads during system overload conditions according to the distribution system requirements. In the numerical analysis, the three different levels of utility load forecasts were considered to evaluate the possibility of changing consumer appliance to different times of the day to help the local substation to provide an uninterrupted power supply without having to turn on additional generation units or buying power from nearby sellers. The analysis shows the number of appliances rescheduled for all the utility forecasts. On average, the rescheduling was successful in the curtailing the peak demands. As expected, it created some extra demands at lower demand periods. This would suggest, that the lower demand times can support extra demand and also support the distribution system requirements.

\subsection{Future Work}

The future scope of this thesis can be extended to following topics.

1) Inclusive of a cost model that could use to show the rescheduling has lowered the Utility generating costs by assigning different prices for different levels of Utility's forecasted load.

2) A surveyed consumer appliance usage data including their preference time to use such appliances if the requested time is not available. This would give a better understanding of consumer needs and behavior. Also, unexpected proffered time would benefit this model by being able to reschedule loads to those times. 
3) The active consumer participation can be used to evaluate how much power can be rescheduled by the utility depending on a number of customers at different percentage level at each node.

4) Increase the number of schedulable appliances types such as a thermostat, HVAC etc. and prioritize the appliance to be scheduled without randomizing. Rescheduling of larger power consuming appliance from one house rather than electric iron from 20 houses, benefit the consumers by reducing a number of consumers needed to be affected.

5) Also, the increasing number of DGs can be used to evaluate the demand profile at a house with DG with a regular house without DG. 
REFERENCES 


\section{REFERENCES}

[1] World Bank Group, "Access to electricity (\% of population)," [Online]. Available: https://data.worldbank.org/indicator/EG.ELC.ACCS.ZS. [Accessed November 2017].

[2] J. Vardakas, N. Zorba and C. Verikoukis, "A Survey on Demand Response Programs in Smart Grids: Pricing Methods and Optimization Algorithms," IEEE Communication Surveys \& Tutorials, vol. 17, no. 1, 2015.

[3] Commonwealth Edison Company,, "ComEd," [Online]. Available: https://www.comed.com/WaysToSave/ForYourHome/Pages/HourlyPricing.aspx. [Accessed October 2017].

[4] R. Stamminger, "Synergy Potential," EIE , D2.3 of WP 2 from the Smart-A project, November 2008 .

[5] A. Safdarian, M. Fotuhi-Firuzabad and M. Lehtonen, "Benefits of Demand Response on Operation of Distribution Networks: A Case Study," IEEE Systems Journal, vol. 10, no. 1, pp. 189 - 197, 2016.

[6] M. Khan and V. Aravinthan, "Impacts of demand-control time period on distribution system and consumer comfort," in Power Systems Conference (PSC), 2016 Clemson University.

[7] Quora, "At what time in morning does a solar panel starts generating electricity? And at what minimum intensity?," [Online]. Available: https:/www.quora.com/At-what-time-inmorning-does-a-solar-panel-starts-generating-electricity-And-at-what-minimum-intensity. [Accessed November 2017].

[8] Power Saving, "Saving Power at Home \& Work," [Online]. Available: http://powersaving.co.za/appliance-tests/kitchen-appliances/dishwasher/. [Accessed May 2017].

[9] Whirlpool Corporation, "Transfer-Free Laundry: Whirlpool® Introduces Smart All-in-One Care $^{\mathrm{TM}}$ Washer and Dryer Combo," 9 Jan 2017. [Online]. Available: http:/www.whirlpoolcorp.com/transfer-free-laundry-whirlpool-introduces-smart-all-inone-care-washer-and-dryer-combo/. [Accessed May 2017].

[10] M. Pipattanasomporn, M. Kuzlu, S. Rahman and Y. Teklu, "Load Profiles of Selected Major," IEEE TRANSACTIONS ON SMART GRID, vol. 5, no. 2, 2014.

[11] N. Nandasiri, A. Gholizadeh, C. Pang and V. Aravinthan, "Reactive power management of co-located residential PVs for radial distribution systems," in Information and Automation for Sustainability (ICIAfS), 2014. 


\section{REFERENCES}

[12] ANSI Std. C84.1-1995, "Electric Power Systems and Equipment Voltage Ratings".

[13] IEEE, "IEEE Four node bus system," 2012.

[14] MathWorks, "fmincon," [Online]. Available: https://www.mathworks.com/help/optim/ug/fmincon.html. [Accessed November 2017].

[15] P. Yang, P. Chavali and A. Nehorai, "Parallel Autonomous Optimization of Demand Response with Renewable Distributed Generators," in IEEE SmartGridComm 2012 Symposium-, 2012.

[16] R. Deng, Z. Yang, M. Chow and J. Chen, "A Survey on Demand Response in Smart Grids: Mathematical Models and Approaches," IEEE Trans. Industrial Informatics, vol. 11, no. 3, 2015.

[17] L. Hernandez, C. Baladron, J. M. Aguiar, B. Carro, A. J. Sanchez-Esguevillas, J. Lloret and J. Massana, "A Survey on Electric Power Demand Forecasting: Future Trends in Smart Grids, Microgrids and Smart Buildings," IEEE Communications Surveys \& Tutorials, vol. 16, no. 3, Third Quarter 2014.

[18] V. C. Gungor, D. Sahin, T. Kocak, S. Ergut, C. Buccella, C. Cecati and G. P. Hancke, "A Survey on Smart Grid Potential Applications and Communication Requirements," IEEE Transactions on Industrial Informatics, vol. 9, no. 1, pp. 28-42, 2012.

[19] M. Doostizadeh and H. Ghasemi, "A Day-Ahead Electricity Pricing Model Based on Smart Metering and Demand-Side Management," Elsevier Energy Journal, vol. 46, pp. 221-230, 2012. 